\title{
Chronic central leptin infusion modulates the glycemia response to insulin administration in male rats through regulation of hepatic glucose metabolism
}

\author{
Emma Burgos-Ramos ${ }^{\text {a, b }}$, Sandra Canelles a, c, Amaia Rodríguez ${ }^{\text {c, d }}$, \\ Javier Gómez-Ambrosi ${ }^{\text {c, }}{ }^{\text {, }}$, Laura M. Frago ${ }^{\text {a, c }}$, Julie A. Chowen ${ }^{\text {a, c }}$, Gema Frühbeck ${ }^{c, d}$, \\ Jesús Argente ${ }^{\mathrm{a}, \mathrm{c}}$, Vicente Barrios ${ }^{\mathrm{a}, \mathrm{c}, *}$ \\ a Department of Endocrinology, Hospital Infantil Universitario Niño Jesús, Instituto de Investigación La Princesa, Department of Pediatrics, Universidad \\ Autónoma de Madrid, Madrid, E-28009, Spain \\ b IMDEA Food, CEI UAM+CSIC, Carretera de Cantoblanco 8, Madrid, E-28049, Spain \\ c Centro de Investigación Biomédica en Red de Fisiopatología de la Obesidad y Nutrición (CIBEROBN), Instituto de Salud Carlos III, Madrid, E-28009, Spain \\ ' Metabolic Research Laboratory, Clínica Universidad de Navarra, IdiSNA, Pamplona, E-31008, Spain
}

\section{A R T I C L E I N F O}

\section{Article history:}

Received 12 March 2015

Received in revised form

6 August 2015

Accepted 9 August 2015

Available online 18 August 2015

\section{Keywords:}

Glycemia

Glycogen synthesis

Insulin signaling

Leptin

Liver

SH-phosphotyrosine phosphatase 1

\begin{abstract}
A B S T R A C T
Leptin and insulin use overlapping signaling mechanisms to modify hepatic glucose metabolism, which is critical in maintaining normal glycemia. We examined the effect of an increase in central leptin and insulin on hepatic glucose metabolism and its influence on serum glucose levels. Chronic leptin infusion increased serum leptin and reduced hepatic SH-phosphotyrosine phosphatase 1, the association of suppressor of cytokine signaling 3 to the insulin receptor in liver and the rise in glycemia induced by central insulin. Leptin also decreased hepatic phosphoenolpyruvate carboxykinase levels and increased insulin's ability to phosphorylate insulin receptor substrate-1, Akt and glycogen synthase kinase on Ser9 and to stimulate glucose transporter 2 and glycogen levels. Peripheral leptin treatment reproduced some of these changes, but to a lesser extent. Our data indicate that leptin increases the hepatic response to a rise in insulin, suggesting that pharmacological manipulation of leptin targets may be of interest for controlling glycemia.
\end{abstract}

(c) 2015 Elsevier Ireland Ltd. All rights reserved.

\section{Introduction}

The liver is a key regulator of glucose homeostasis due to its ability to store glucose as glycogen and to release it according to peripheral demands (Jiao et al., 2013). Under physiological conditions insulin regulates these fluxes by modifying transport into the

Abbreviations: $\alpha$-MSH, $\alpha$-melanocyte stimulating hormone; Akt, protein kinase $\mathrm{B}$; AQP9, aquaglyceroporin-9; DU, densitometry units; ER, endoplasmic reticulum; GSK3 $\beta$, glycogen synthase kinase-3 $\beta$; GLUT2, glucose transporter 2; IL, interleukin; IR, insulin receptor; IRS1, insulin receptor substrate 1; JAK2, Janus kinase 2; JNK, cJun N-terminal kinase; MFI, median fluorescence intensity; OB-Rb, long form of leptin receptor; PEPCK, phosphoenolpyruvate carboxykinase; PI3K, phosphatidylinositol-3 kinase; p85, regulatory subunit of PI3K; p110, catalytic subunit of PI3K; SH-PTP1, SH-phosphotyrosine phosphatase 1; SOCS3, suppressor of cytokine signaling 3; STAT3, signal transducer and activator of transcription factor 3.

* Corresponding author. Department of Endocrinology, Hospital Infantil Universitario Niño Jesús, Avda. Menéndez Pelayo, 65, E-28009, Madrid, Spain.

E-mail address: vicente.barriossa@salud.madrid.org (V. Barrios). hepatocyte and suppressing the expression of genes involved in gluconeogenesis. Leptin also participates in the control of glycemia, promoting glucose uptake and glycogen storage through stimulation of phosphatidylinositol (PI)-3 kinase in the liver (Kellerer et al., 1997).

Leptin and insulin regulate glycemia by acting on both central and peripheral tissues and share several signaling targets in this process (Li et al., 2011; D'Souza et al., 2014; Crépin et al., 2014). Leptin acting centrally modulates peripheral insulin signaling through several mechanisms, including changes in peripheral hormones that affect insulin sensitivity and glucose metabolism (Hidaka et al., 2002; Cettour-Rose et al., 2005; Bartell et al., 2011). In liver, insulin-dependent glucoregulatory mechanisms are modulated by phosphatases and kinases that regulate intracellular targets and their interactions. Indeed, association of insulin receptor (IR) with suppressor of cytokine signaling 3 (SOCS3) and SHphosphotyrosine phosphatase 1 (SH-PTP1) are determining factors in hepatic glucoregulation (Oriente et al., 2011). The 
relationship between central and peripheral signaling and the actions of leptin and insulin are more evident in obesity, as in most instances these subjects exhibit insulin resistance related to an increase in proinflammatory cytokines that aggravate this pathological situation (Dali-Youcef et al., 2013). Although the contribution of adipose tissue to obesity related inflammation has been reported (Kulyté et al., 2014), the role of the liver in the generation of a pro- or anti-inflammatory profile remains unclear.

The effect of exogenous leptin on insulin's actions and metabolic outputs in peripheral tissues has been analyzed in models of obesity and diabetes (Roman et al., 2010). However, there is little information regarding the effects of an increase in central leptin and insulin bioavailability on hepatic insulin sensitivity and its relationship with interleukin levels and carbohydrate metabolism in non-obese animals. Leptin decreases food intake and could modify insulin sensitivity and hepatic glucose metabolism; hence it would be important to discriminate the direct effects of leptin from those due to decreased food intake (de Vries et al., 2014). Therefore, we asked whether chronic central leptin infusion could improve hepatic insulin signaling and glycemia in response to an insulin bolus in a non-obese experimental model and the possible involvement of systemic changes in this response. To discriminate between the direct effects of leptin and those due only to a reduction in food intake, a group of pair-fed rats were included.

\section{Material and methods}

\subsection{Animals}

This study was approved by the Ethics Committee of the Universidad de Alcalá de Henares (SAF 22277, Ministerio de Ciencia y Tecnología) and complied with Royal Decree 53/2013 pertaining to the protection of experimental animals and with the European Communities Council Directive (2010/63/EU).

\subsubsection{Central leptin and insulin infusion}

Thirty-six adult male Wistar rats $(250 \pm 10 \mathrm{~g})$ were individually caged with a 12-h light/dark cycle and fed standard chow and water ad libitum. After an overnight fast, rats were anesthetized (4 mg of ketamine/100 $\mathrm{g}$ bw and $0.5 \mathrm{mg}$ of xylazine/100 $\mathrm{g} \mathrm{bw}$ ) and positioned in a stereotaxic apparatus. A cannula attached to an osmotic minipump (Alzet, Durect Corporation, Cupertino, CA) containing either saline or leptin (Preprotech, Rocky Hill, NJ, USA; $12 \mu \mathrm{g} /$ day with a delivery volume of $0.5 \mu \mathrm{l} / \mathrm{h}$ ) with $1 \% \mathrm{BSA}$ was implanted into the right cerebral ventricle $(-0.3 \mathrm{~mm}$ anteroposterior, $1.1 \mathrm{~mm}$ lateral from Bregma) and maintained during 14 days, and another cannula linked to a catheter in the rat left lateral cerebral ventricle where insulin was injected. Previously, in order to verify the stereotactic coordinates, three male rats received an icv injection of $7 \mu \mathrm{l}$ 0.4\% Trypan Blue solution (Sigma-Aldrich, St. Louis, MO, USA) and were killed 2 h later (Miller et al., 2006). To discriminate the inhibitory effect of leptin on appetite, a pair-fed group was included. Food intake and body weight were measured daily. On the last day, including a fasting period of $12 \mathrm{~h}, 10 \mathrm{mU}$ of insulin (Novo Nordisk Pharma, Madrid, Spain) in $7 \mu$ l PBS or PBS was injected icv and the rats sacrificed by decapitation $2 \mathrm{~h}$ later. Glycemia was measured before and $2 \mathrm{~h}$ after PBS or insulin administration (Accu-Check Sensor, Roche, Mannheim, Germany). This resulted in the following groups ( $n=6$ per group): chronic vehicle plus acute vehicle (control), chronic vehicle plus insulin (insulin), pair-fed group with chronic vehicle and acute vehicle (pair-fed), pair-fed group with chronic vehicle plus acute insulin (pair-fed plus insulin), chronic leptin plus acute vehicle (leptin) and chronic leptin plus acute insulin (leptin plus insulin).

A dose of leptin that might be considered supra-physiological was chosen for this study as it is known to exert an effect on food intake (Friedman and Halaas, 1998; Banks and Lebel, 2002). With respect to insulin, brain levels are 10-100 times higher than in blood and studies using higher icv insulin doses have been considered to be in the physiological range (Tanaka et al., 2000). Therefore, the dose employed in this study could be considered to be in the physiological range and compatible with variations between fed and fasting states (Havrankova et al., 1978). A two-hour post-insulin injection interval was chosen because at one hour differences in activation of some signaling targets were observed, but not in parameters related to metabolism. At longer timeperiods changes in the activation of many signaling targets were no longer detectable.

\subsubsection{Oral glucose tolerance test}

To determine how chronic central leptin infusion affects glucose metabolism, an oral glucose tolerance test (OGTT) was performed in control, pair-fed and central leptin-treated rats ( $\mathrm{n}=4$ per group). After 14 days of central saline or leptin ( $12 \mu \mathrm{g} / \mathrm{day})$ infusion and a fasting period of $12 \mathrm{~h}$, glucose ( $2 \mathrm{~g} / \mathrm{kg}$ body weight) dissolved in water was administered orally using gavage tubes (Suresha et al., 2013). Blood samples were extracted from the tail vein before administration of a glucose bolus and at 15, 30, 60,120 and 180 min for determination of glucose levels (Accu-Check Sensor).

\subsubsection{Intraperitoneal insulin tolerance test}

Insulin sensitivity was assessed after overnight fasting by performing an intraperitoneal insulin tolerance test (IPITT) in control, pair-fed and central leptin-treated rats ( $n=4$ per group). After the injection of a bolus of $2 \mathrm{U} / \mathrm{kg}$ of insulin, blood samples were drawn consecutively at $15,30,60,90,120$ and 180 min for glucose measurement (Ndisang et al., 2010), as described above.

\subsubsection{Peripheral leptin and central insulin administration}

Sixteen adult male Wistar rats $(250 \pm 10 \mathrm{~g})$ were anesthetized as stated above and received either saline $(n=8)$ or leptin $(n=8$, $0.2 \mathrm{mg} / \mathrm{kg} /$ day) via a subcutaneously implanted Alzet osmotic minipump (Scarpace et al., 2000). After 14 days, $10 \mathrm{mU}$ of insulin (in $7 \mu \mathrm{l}$ PBS) or PBS alone was injected icv and the rats sacrificed by decapitation $2 \mathrm{~h}$ later. This resulted in the following groups $(\mathrm{n}=4$ per group): chronic peripheral vehicle plus acute central vehicle (control), chronic peripheral vehicle plus acute central insulin (insulin), chronic peripheral leptin plus acute central vehicle (leptin) and chronic peripheral leptin plus acute central insulin (leptin plus insulin).

\subsection{Hormone measurements}

Serum leptin and insulin concentrations were determined using ELISA kits from Millipore Corporate Headquarters (Billerica, MA, USA). Serum glucagon and acylated and total ghrelin were measured by using RIA kits from Millipore. Serum $\alpha$-melanocyte stimulating hormone ( $\alpha-\mathrm{MSH})$ levels were evaluated by an ELISA kit from Cusabio (Wuhan, China). The intra- and inter-assay variations were lower than $10 \%$ in all cases.

\subsection{Immunoprecipitation}

The associations between targets were studied by immunoprecipitation. Thirty mg of liver were homogenized on ice in $500 \mu \mathrm{l}$ of lysis buffer pH 7.6 containing $50 \mathrm{mmol} / 1$ HEPES, $10 \mathrm{mM}$ EDTA, $50 \mathrm{mmol} / \mathrm{l}$ sodium pyrophosphate, $100 \mathrm{mmol} / \mathrm{l} \mathrm{NaF}, 10 \mathrm{mmol} / \mathrm{l}$ $\mathrm{Na}_{3} \mathrm{VO}_{4}, 1 \%$ Triton X-100, $2 \mathrm{mmol} /$ lphenylmethylsulfonyl fluoride, $10 \mu \mathrm{g} / \mathrm{ml}$ leupeptin and $10 \mu \mathrm{g} / \mathrm{ml}$ aprotinin. Before immunoprecipitation, liver homogenates were centrifuged twice at $12,000 \mathrm{~g}$ 
for $5 \mathrm{~min}$ and $500 \mu \mathrm{g}$ of protein were immunoprecipitated overnight at $4{ }^{\circ} \mathrm{C}$ with the corresponding antibodies and incubated with protein A-agarose beads for $2 \mathrm{~h}$ at $4{ }^{\circ} \mathrm{C}$. Immunocomplexes were washed with lysis buffer, extracted for $5 \mathrm{~min}$ at $95{ }^{\circ} \mathrm{C}$ in $2 \mathrm{X}$ SDSPAGE sample buffer ( $200 \mathrm{mmol} / \mathrm{lTris}-\mathrm{HCl}, 10 \% \mathrm{SDS}, 0.01 \mathrm{M}$ bromophenol blue, 8\% 2-mercaptoethanol, 20\% glycerol, pH 7.6) and analyzed by Western blotting as described below.

\subsection{Western blotting}

Western blots for immunocomplexes and hepatic homogenates were performed using antibodies against phosphorylated (p) Tyr705-signal transducer and activator of transcription factor 3 (pTyr705-STAT3), pSer727-STAT3 and SOCS3 from Cell Signaling Technology (Danvers, MA), pTyr1007/1008 Janus kinase 2 (pJAK2), JAK2 and regulatory subunit of PI3K (p85) from Millipore (Temecula, CA), STAT3 from R\&D Systems (Minneapolis, MN) and aquaglyceroporin-9 (AQP9), the beta chain of insulin receptor (IR $\beta$ ), catalytic subunit of PI3K (p110), GLUT2, long form of the leptin receptor $(\mathrm{OB}-\mathrm{Rb})$, phosphoenolpyruvate carboxykinase (PEPCK) and SH-PTP1 from Santa Cruz Biotechnology (Santa Cruz, CA). The proteins were detected by chemiluminiscence using an ECL system. Quantification of the bands was carried out by densitometry using a Kodak Gel Logic 1500 Image Analysis system and Molecular Imaging software 4.0 (Rochester, NY, USA). AQP9, GLUT2, IR $\beta$, OB-Rb, p85, PEPCK, SOCS3 and SH-PTP1 were normalized with actin (Thermo Scientific, Fremont, CA), whereas pJAK2, pTyr705-STAT3 and p-Ser727- STAT3 were normalized with their respective total forms.

\subsection{Multiplexed bead immunoassay}

Phosphorylated and total levels of glycogen synthase kinase- $3 \beta$ (GSK3 $\beta$ ), insulin receptor substrate 1 (IRS1), Akt and c-Jun N-terminal kinase (JNK) and serum and hepatic IL-2, IL-4, IL-6 and IL-10 were determined by multiplexed bead immunoassays (Bio-Rad Laboratories, Madrid, Spain and Millipore; respectively), following the manufacturer's recommendations. A minimum of 50 beads per parameter were analyzed in the Bio-Plex suspension array system 200 (Bio-Rad). Raw data (median fluorescence intensity, MFI) were analyzed with the Bio-Plex Manager Software 4.1 (Bio-Rad Laboratories).

\subsection{Measurement of hepatic glucose and glycogen}

Liver samples $(1 \mathrm{~g})$ were incubated with $2 \mathrm{ml}$ potassium hydroxide $30 \%$ at $100{ }^{\circ} \mathrm{C}$ for $15 \mathrm{~min}$. The tissue debris was removed by centrifugation at $2000 \mathrm{~g}$ for $5 \mathrm{~min}$, the supernatants precipitated with $200 \mu \mathrm{l}$ sodium sulfate plus $4 \mathrm{ml}$ ethanol and then cooled on ice for $15 \mathrm{~min}$. Glycogen pellets were obtained by centrifugation at $2000 \mathrm{~g}$ for $5 \mathrm{~min}$ and hydrolyzed with $1 \mathrm{ml}$ sulfuric acid $5 \mathrm{~N}$ and boiled for $45 \mathrm{~min}$. The samples were neutralized and glucose concentration determined by an enzymatic method from Sigma-Aldrich (GAGO-20).

\subsection{Immunohistochemistry and nuclear staining}

Fluorescent immunohistochemistry was performed on frozen $10 \mu \mathrm{m}$ cryostat sections that were fixed in $4 \%$ paraformaldehyde ( $\mathrm{w} /$ v) for 20 min, washed, blocked with PBS containing 3\% BSA and $1 \%$ Triton X-100 for $90 \mathrm{~min}$ and incubated $48 \mathrm{~h}$ at $4{ }^{\circ} \mathrm{C}$ with anti-Akt (1:300, Santa Cruz Biotechnology) with blocking buffer. Sections were washed and incubated for $120 \mathrm{~min}$ at RT with anti-goat IgG biotin (1:1000, Thermo Scientific) with blocking buffer. Afterwards, sections were washed and incubated under dark conditions with streptavidin Alexa Fluor 488 (1:2000, Molecular Probes, Leiden, The Netherlands) in blocking buffer for $120 \mathrm{~min}$ at RT and washed three times with PBS containing $0.1 \%$ BSA and $0.1 \%$ Triton X-100. Sections were incubated for $5 \mathrm{~min}$ at RT with DRAQ5 (1:5000, BioStatus Ltd., Leics, United Kingdom) in PBS, mounted and cover-slipped with Clear Mount (Electronic Microscopy Sciences, Hatfield, PA). Immunofluorescence was visualized with a DM IRB confocal microscope (Leica, Wetzlar, Germany).

\subsection{RNA purification and real time PCR analysis}

Total RNA was extracted from $50 \mathrm{mg}$ of inguinal fat according to the Tri-Reagent protocol (Sigma, St. Louis, USA). Reverse transcription was performed on $2 \mu \mathrm{g}$ of total RNA using a high-capacity cDNA kit (Applied Biosystems). Real-time PCR was performed in an ABI Prism 7000 Sequence Detection System (Applied Biosystems) using TaqMan PCR Master Mix (Applied Biosystems) and the thermocycler parameters recommended by the manufacturer. PCRs were performed in duplicate in a total volume of $50 \mu \mathrm{l}$, containing $25 \mu \mathrm{l}$ of the reverse transcription reaction. TaqMan gene expression assay were used for analyzing the gene expression of leptin (Rn00565158_m1, Applied Biosystems) following the manufacturer's procedures. Relative gene expression comparison was carried-out using an invariant endogenous control (actin, Rn00667869_m1, Applied Biosystems). According to the manufacturer's guidelines, the $\Delta \Delta C T$ method was used for relative quantification.

\subsection{Statistical analysis}

Data are presented as mean \pm SEM. Statistical comparison to assess a possible interaction between leptin and insulin infusion was performed by two-way ANOVA. Statistical analysis of all data was carried out by one-way ANOVA followed by a Bonferroni's test. Pearson's correlation coefficient $r$ was used to measure the degree of association between different variables in each group. Values were considered significantly different when the $P$ value was less than 0.05 . Statistical analyses were conducted with Prisma software 4.00 (GraphPad, San Diego, CA, USA) with an $\alpha$ level of 0.05.

\section{Results}

\subsection{General characteristics of experimental groups}

Average daily food intake was reduced in the pair-fed, pair-fed plus insulin, leptin and leptin plus insulin groups (Fig. 1A). Body weight gain was lower in the same groups, with a more pronounced reduction in both leptin groups (Fig. 1B). Leptin- and leptin plus insulin-treated rats had less subcutaneous (control: $4.35 \pm 0.19$, control plus insulin: $4.17 \pm 0.28$, pair-fed: $3.12 \pm 0.32$, pair-fed plus insulin: $3.05 \pm 0.16$, leptin: $1.98 \pm 0.15$ and leptin plus insulin: $2.13 \pm 0.20 \mathrm{~g}$ ) and epididymal fat pads (control: $3.72 \pm 0.25$, control plus insulin: $4.03 \pm 0.38$, pair-fed: $2.80 \pm 0.47$, pair-fed plus insulin: $2.65 \pm 0.10$, leptin: $1.64 \pm 0.15$ and leptin plus insulin: $1.49 \pm 0.26 \mathrm{~g}$ ) compared with their respective control or pair-fed groups $(\mathrm{p}<0.01$ for both).

Serum acylated ghrelin was increased in pair-fed and leptintreated rats and rose after insulin treatment with an interaction between leptin and insulin (F: 9.09, p < 0.001), as the insulin induced rise was smaller in the leptin group (Fig. 1C). Total ghrelin levels did not change (data not shown) and glucagon levels were reduced in the pair-fed and leptin-treated groups (Fig. 1D). Serum insulin concentrations were unaffected by leptin or insulin treatments (Fig. 1E). Insulin infusion augmented serum $\alpha$-MSH levels in pair-fed and leptin-treated rats, with this rise being greater in 

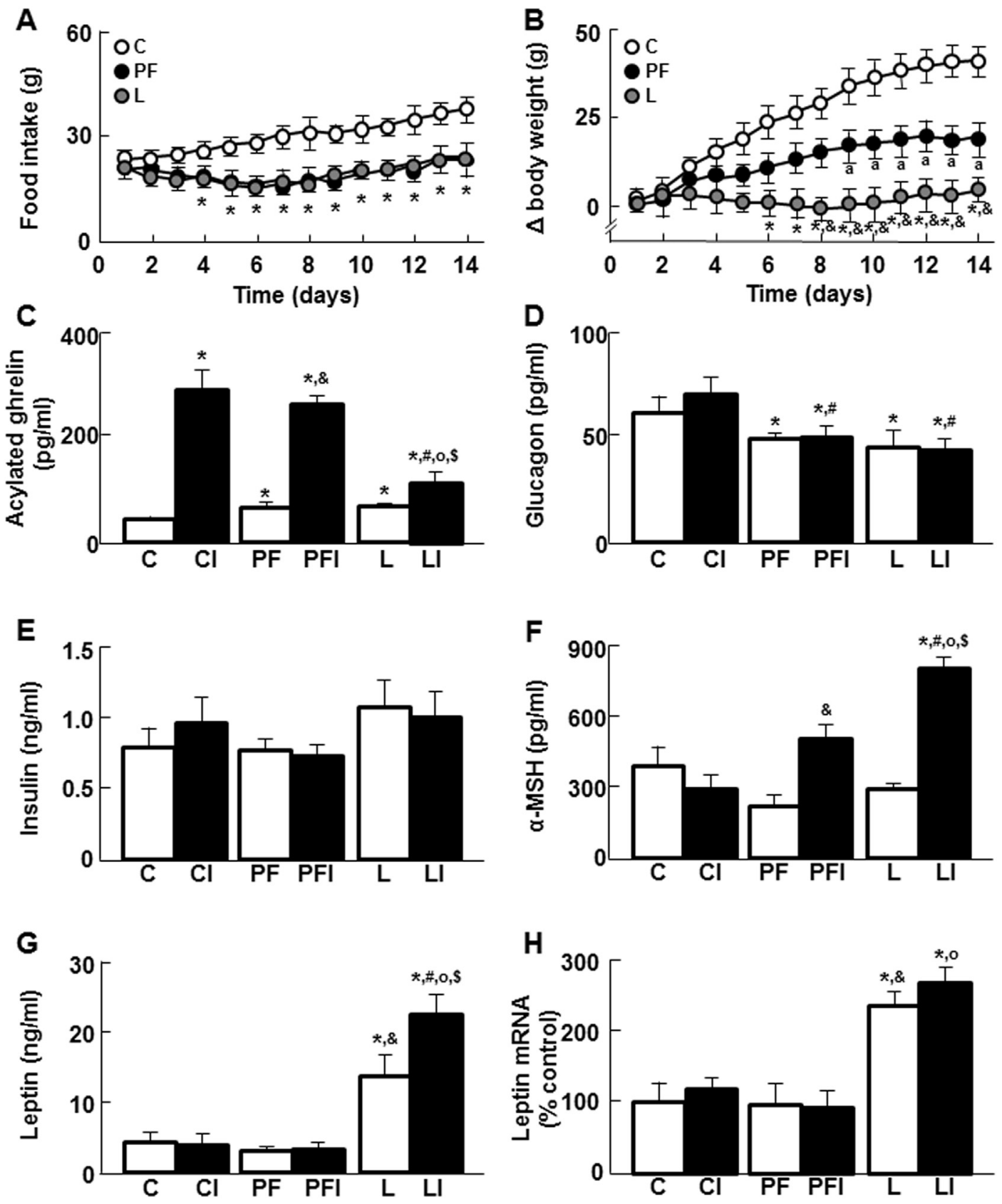

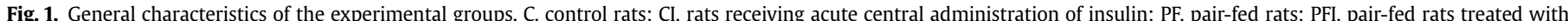

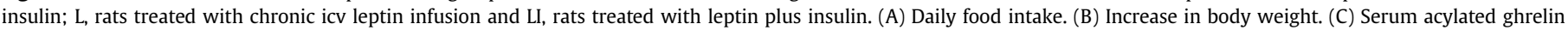

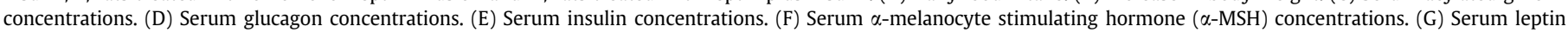

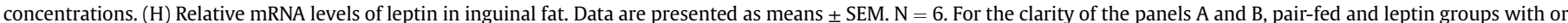

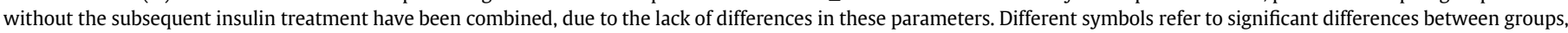

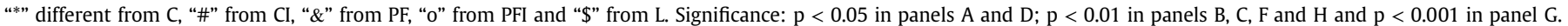

leptin-treated rats (Fig. 1F), with an interaction between leptin and insulin ( $\mathrm{F}: 17.26, \mathrm{p}<0.001$ ).

\subsection{Chronic central leptin infusion increases serum leptin and leptin gene expression}

Serum leptin concentrations were increased in the leptin and leptin plus insulin groups (Fig. 1G). To analyze if adipose tissue contributes to this rise, mRNA levels of leptin were analyzed in subcutaneous and visceral adipose pads. Relative leptin mRNA levels were increased in inguinal fat of the leptin and leptin plus insulin groups (Fig. 1H), with no changes in epididymal fat (data not shown).

3.3. Leptin reduces the rise in glycemia induced by central insulin and lowers serum glucose levels after oral glucose or intraperitoneal insulin administration

Blood glucose levels were in the normal range in all groups, including before insulin administration. However, chronic exposure to increased central leptin attenuated the rise in glycemia induced by central insulin administration (Fig. 2A, interaction leptin and 
insulin: $\mathrm{F}=17.49, \mathrm{p}<0.001)$.

Oral administration of glucose triggered an increase in glycemia in all groups, with this rise being lower in the pair-fed and leptin groups with respect to controls and in leptin-treated rats compared

A

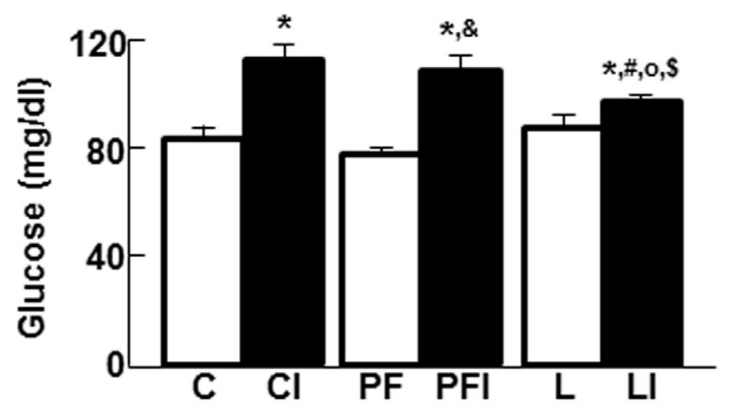

B

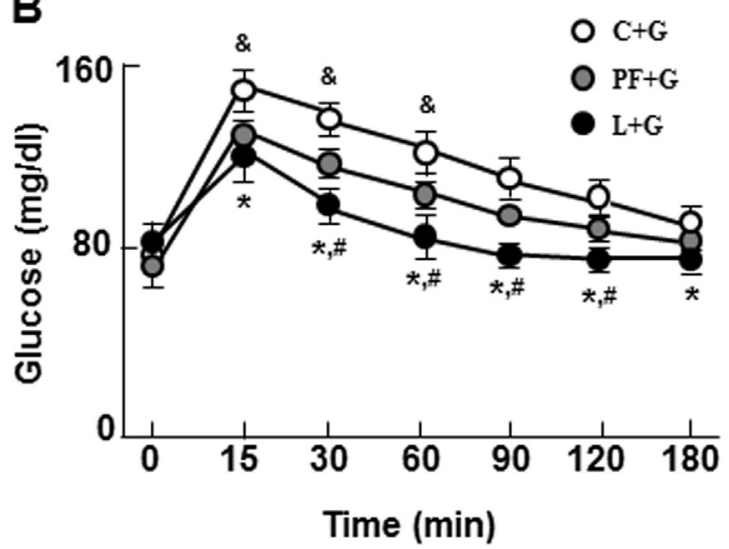

C

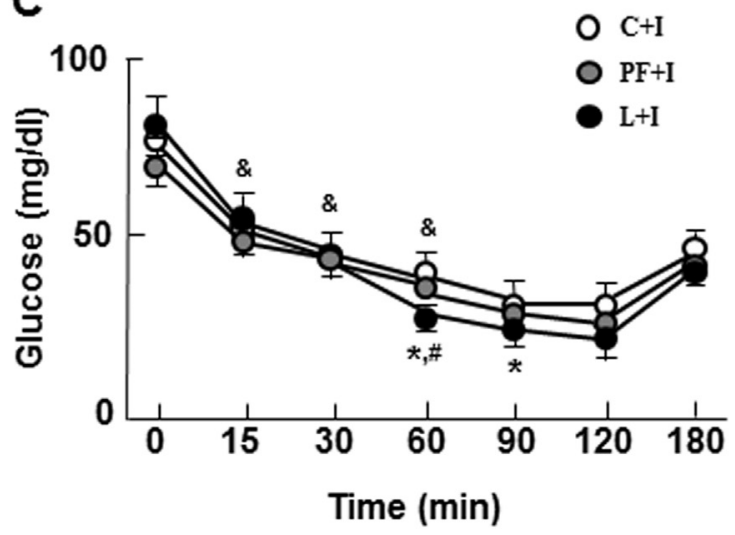

Fig. 2. Serum glucose levels after central insulin infusion, oral glucose tolerance test (OGTT) or intraperitoneal insulin tolerance test (IPITT). (A) Serum glucose levels after central insulin infusion. $\mathrm{C}$, control rats; $\mathrm{CI}$, rats receiving acute central administration of insulin; PF, pair-fed rats; PFI, pair-fed rats treated with insulin; L, rats treated with chronic icv leptin infusion and LI, rats treated with leptin plus insulin. (B) Serum glucose levels before $(0 \mathrm{~min})$ and during $(15,30,60,90,120$ and $180 \mathrm{~min}$ ) an OGTT. $\mathrm{C}+\mathrm{G}$, control rats that received oral glucose; $\mathrm{PF}+\mathrm{G}$, pair-fed rats that received oral glucose; $\mathrm{L}+\mathrm{G}$, rats treated with chronic icv leptin infusion that received oral glucose. (C) Serum glucose levels before ( 0 min) and during (15, 30, 60, 90, 120 and $180 \mathrm{~min})$ an IPITT. C + I, control rats that received an IP insulin bolus; PF + I, pair-fed rats that received an IP insulin bolus; $\mathrm{L}+\mathrm{I}$, rats treated with chronic icv leptin infusion that received an IP insulin bolus. Data are presented as means \pm SEM. $N=4$. Different symbols refer to significant differences between groups or time-period, "*” different from C + G or C + I, "\#" from PF + G or PF + I and "\&" statistical difference vs. previous point. Significance: $\mathrm{p}<0.05$. to the pair-fed group (Fig. 2B). Intraperitoneal (IP) insulin administration provoked a rapid drop in glycemia in all groups, with this decline being more pronounced in leptin-treated rats at 60 and 90 min (Fig. 2C).

\subsection{Central administration of leptin and insulin modifies their signaling pathways in the hypothalamus}

Phosphorylation of STAT3 on Tyr705 was diminished by pairfeeding, with insulin stimulating phosphorylation of this protein only in the leptin-treated group (Fig. 3A). Levels of p110 were increased in leptin treated rats with no effect of insulin in any group (Fig. 3B). Activation of Akt was reduced in pair-fed and augmented in leptin-treated rats, with insulin increasing the degree of
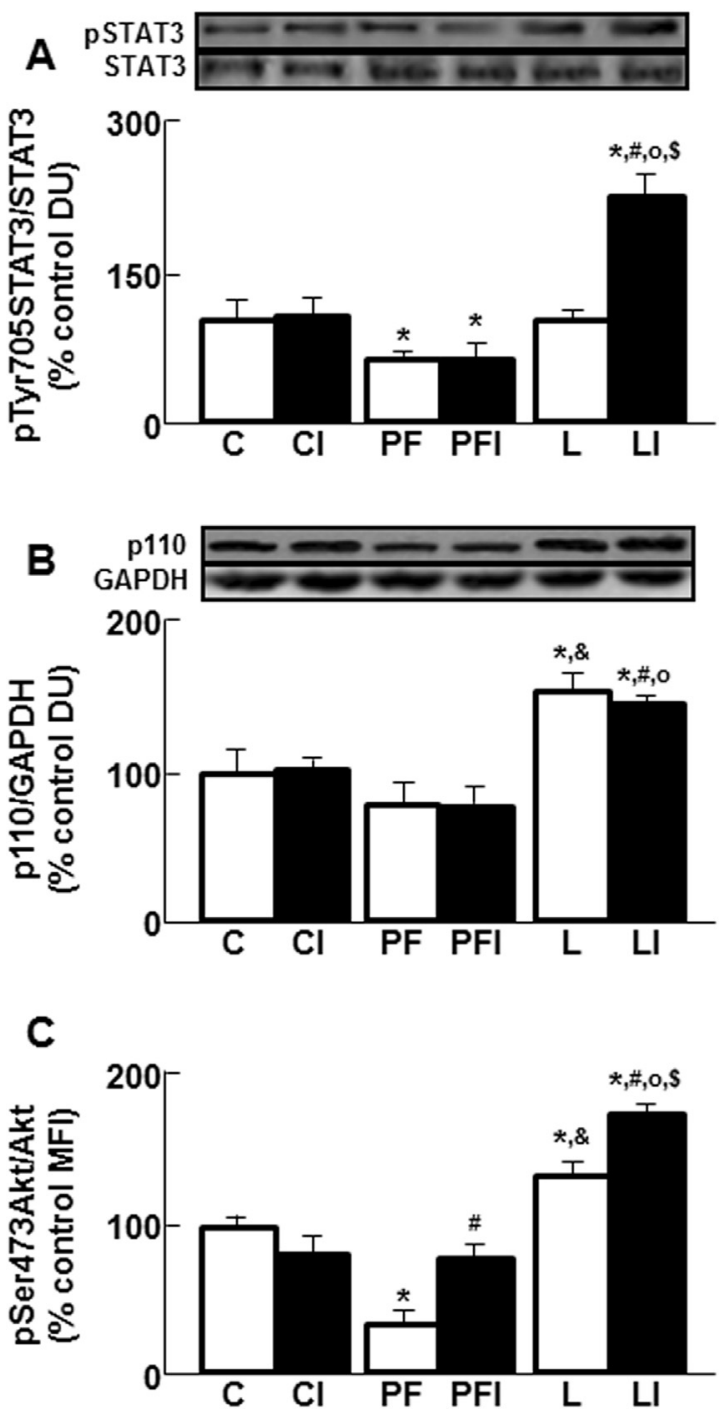

Fig. 3. Leptin infusion activates the PI3K pathway in the hypothalamus. C, control rats; $\mathrm{CI}$, rats receiving acute central administration of insulin; PF, pair-fed rats; PFI, pair-fed rats treated with insulin; $\mathrm{L}$, rats treated with chronic icv leptin infusion and LI, rats treated with leptin plus insulin. (A) Relative signal transducer and activator of transcription 3 (STAT3) phosphorylated on Tyr705 (p-Tyr705-STAT3) protein levels. (B) Relative levels of catalytic subunit of PI3K (p110) protein levels. (C) Relative phosphorylated (p) Akt on serine 473 (pSer473Akt) protein levels. Data are presented as means \pm SEM. $N=6$. DU, densitometry units; MFI, median fluorescent intensity. Different symbols refer to significant differences between groups, “*” different from $C$, “\#” from CI, "\&" from PF, “o" from PFI and "\$” from L. Significance: $\mathrm{p}<0.05$ in panel A; $\mathrm{p}<0.01$ in panel $\mathrm{C}$ and $\mathrm{p}<0.001$ in panel $\mathrm{B}$. 
phosphorylation in both groups, but having no effect in controls (Fig. 3C).

\subsection{The effect of central insulin on hepatic leptin signaling pathways is modulated by central leptin infusion}

There were no differences in OB-Rb protein levels (Fig. 4A). Phosphorylation of JAK2 decreased in response to insulin in control and pair-fed rats and, although leptin alone had no effect, it abolished this response to insulin (Fig. 4B). Phosphorylation of STAT3 on Tyr705 was diminished in pair-fed and leptin-treated rats with no effect of insulin (Fig. 4C) and pSer727-STAT3 levels were lower in leptin treated rats, with a reduction after insulin treatment in pairfed rats (Fig. 4D). No differences in total STAT3 levels (control: $100.0 \pm 7.2$, control plus insulin: $85.6 \pm 9.2$, pair-fed: $97.2 \pm 5.4$, pair-fed plus insulin: $81.7 \pm 8.9$, leptin: $103.6 \pm 7.0$ and leptin plus
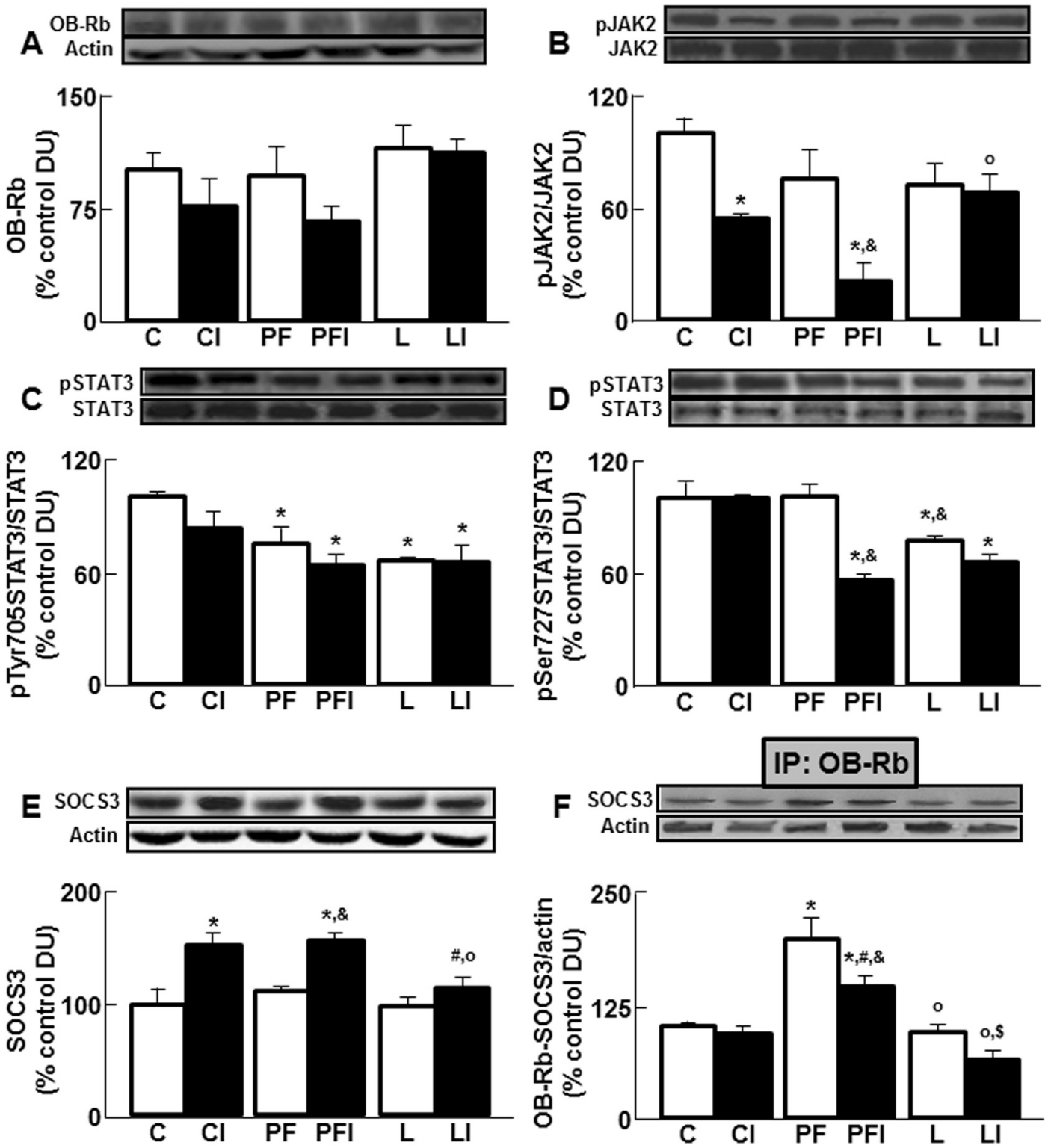

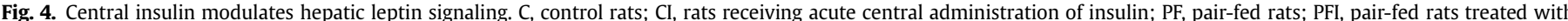

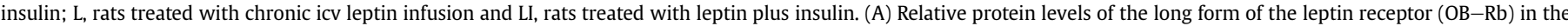

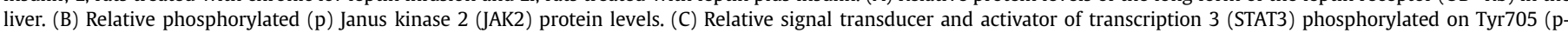

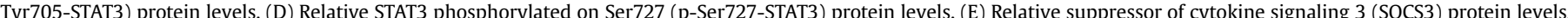

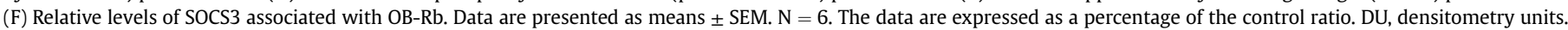

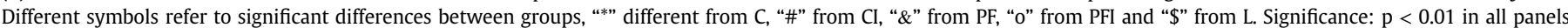



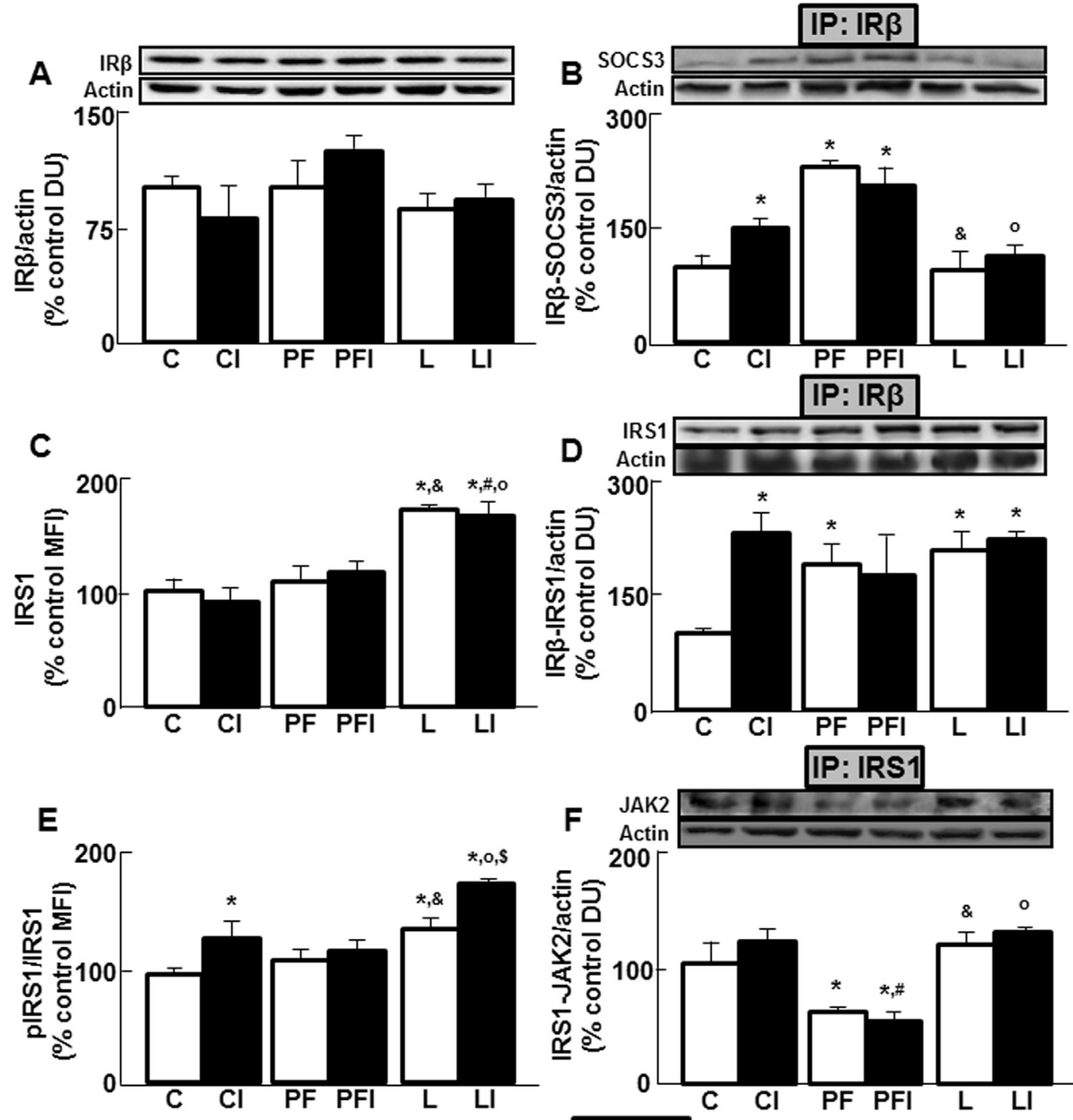

\section{IP: IRS1}
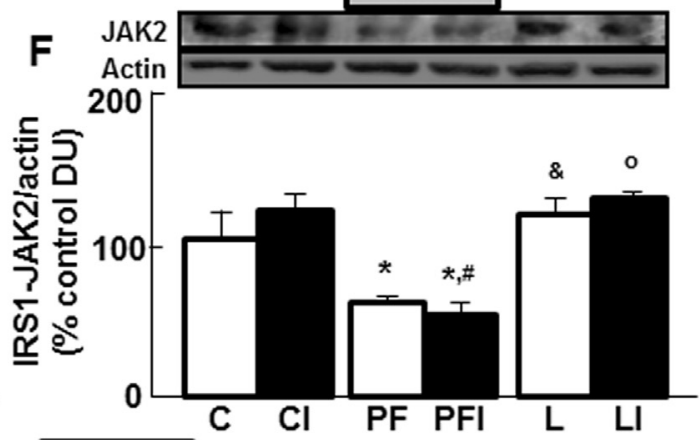

IP: IRS1

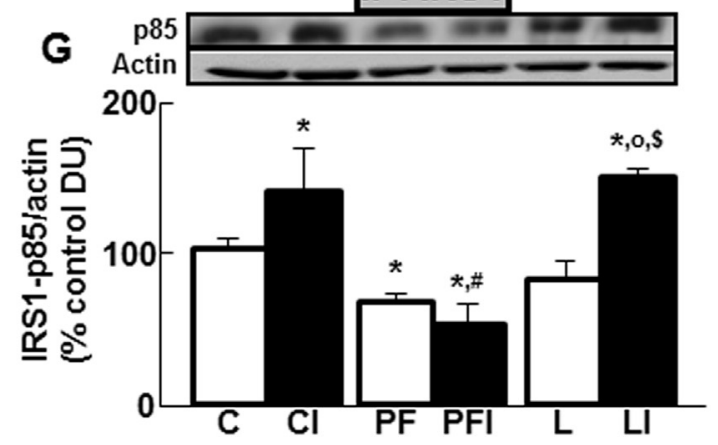

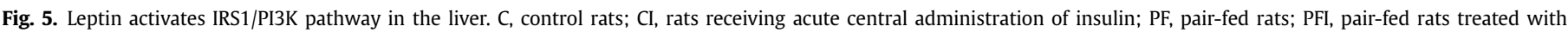

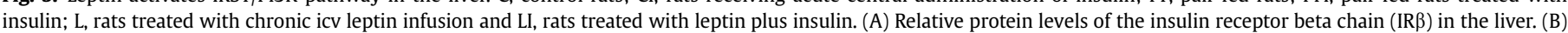

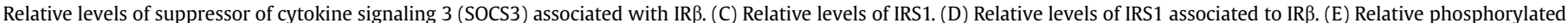

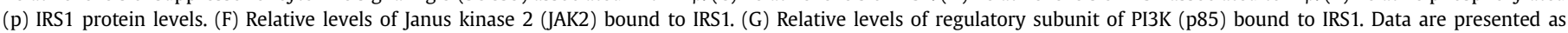

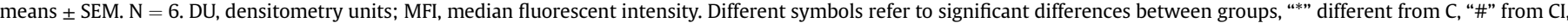
"\&" from PF, “o" from PFI and "\$” from L. Significance: $\mathrm{p}<0.05$ in panels B, D and E and p $<0.01$ in panel C.

modified the ability of insulin to induce IR $\beta$-SOCS3 association $(\mathrm{F}=4.18, \mathrm{p}<0.05)$. Association of SOCS3 to IR $\beta$ was increased in pair-fed rats and in controls after insulin treatment (Fig. 5B). Total IRS1 was increased by leptin, with no influence of insulin (Fig. 5C).
The association of IRS1 to IR $\beta$ was increased in pair-fed and leptintreated rats, with insulin having a stimulatory effect only in controls (Fig. 5D). Leptin augmented IRS1 phosphorylation, with a positive effect of insulin in the control and leptin groups (Fig. 5E, 
interaction treatment and insulin: $\mathrm{F}=7.24, \mathrm{p}<0.01$ ).

Association of IRS1 to JAK2 was diminished in pair-fed rats, with no effect of insulin (Fig. 5F). Leptin did not change IRS1-p85 association; however, insulin increased it in control and leptin-treated rats, but not in pair-fed rats (Fig. 5G). Linear regression analyses showed correlations between IR $\beta$-IRS1 and IRS1-JAK2 $(\mathrm{r}=0.58$, $\mathrm{p}<0.01)$ and between IRS1-JAK2 and IRS1-p85 ( $\mathrm{r}=0.45, \mathrm{p}<0.05)$. Leptin augmented Akt phosphorylation, with insulin increasing pAkt in all groups and having a greater effect in leptin-treated rats (Fig. 6A). Immunolocalization studies showed that after insulin infusion, Akt was preferentially located in the cytoplasm in control and pair-fed groups, whereas in leptin-treated rats was also detected in the nucleus (Fig. 6B to J).

\subsection{Activation of the IRS1/PI3K pathway is related to a reduction in JNK phosphorylation and SH-PTP1 levels}

Phosphorylation of JNK and SH-PTP1 levels is negatively regulated by insulin in control rats (Fig. $6 \mathrm{~K}$ and L, respectively). Leptin also decreased JNK phosphorylation and SH-PTP1 levels, with insulin having no effect in leptin-treated rats. Insulin decreased pJNK and SH-PTP1 in pair-fed rats, with this decline being significant only in the latter.

\subsection{Chronic leptin exposure modifies levels and association of targets related to hepatic insulin sensitivity}

No change in serum IL-6 or IL-10 levels was found (Fig. 7A and B, respectively). There was an interaction between treatment and insulin on serum IL-2 levels $(F=5.70, p<0.01)$. IL-2 was augmented in leptin-treated rats and insulin increased it in control and pair-fed and reduced it in leptin-treated rats (Fig. 7C). Serum IL4 was increased in leptin and leptin plus insulin-treated rats (Fig. 7D).

The hepatic content of IL-6 was augmented in pair-fed and leptin-treated rats, with an increase after insulin in the pair-fed group (Fig. 7E), with an interaction between treatment and insulin (F: 6.12, p < 0.01). Leptin had no effect on IL-10 levels, but blocked the insulin induced rise seen in the control and pair-fed groups (Fig. 7F). Liver IL-2 levels were increased in the pair-fed group and diminished in leptin-treated rats (Fig. 7G). Hepatic IL-4 content augmented after leptin infusion and insulin increased it in pair-fed and leptin-treated rats (Fig. $7 \mathrm{H}$ ).

\subsection{Leptin increases GLUT2 and reduces PEPCK levels in the liver}

To test the possible role of the liver in the changes observed in glycemia, we analyzed serum glycerol levels, which were increased in pair-fed rats (Fig. 8A). In addition, levels of GLUT2 were measured. Leptin augmented hepatic GLUT2 and insulin treatment increased it only in controls (Fig. 8B). Leptin diminished PEPCK levels, with insulin having an inhibitory effect in controls (Fig. 8C, interaction treatment and insulin: $\mathrm{F}=3.95, \mathrm{p}<0.05$ ). Hepatic AQP9, which captures glycerol for gluconeogenesis (Rodríguez et al., 2011), was reduced in leptin-treated rats (Fig. 8D).

\subsection{Central insulin effects on glycogen synthesis are potentiated by leptin}

Total GSK3 $\beta$ levels were decreased in leptin-treated rats (Fig. 8E). Leptin increased GSK3 $\beta$ phosphorylation on serine 9 with a stimulatory effect of insulin in this group (Fig. 8F, interaction treatment and insulin: $\mathrm{F}=246.96, \mathrm{p}<0.001$ ). Hepatic glycogen content was reduced in pair-fed rats and insulin increased glycogen only in leptin-treated rats (Fig. 8G, interaction: $F=19.24, p<0.001$ ).

\subsection{Effect of peripheral leptin on food intake, body weight, serum} hormone levels and hepatic insulin signaling

Average daily food intake was reduced after peripheral leptin administration (Fig. 9A). Body weight gain at the end of study was also lower (Fig. 9B). Serum leptin was augmented in the leptin and leptin plus insulin groups (Fig. 9C) and glucagon levels were unchanged in the leptin-treated groups (Fig. 9D). Serum insulin levels were unchanged (data not shown). Insulin infusion increased serum $\alpha$-MSH levels in leptin-treated rats (Fig. 9E).

When hepatic insulin signaling was analyzed, insulin increased phosphorylation of IRS1 in leptin-treated rats (Fig. 9F). Akt activation was not affected by leptin treatment, with insulin increasing pAkt levels in both control and leptin-treated rats, with no differences between them (Fig 9G). Finally, leptin did not modify hepatic glycogen levels, but insulin increased glycogen only in leptintreated rats (Fig. 9H, interaction leptin and insulin: $F=5.87$, $\mathrm{p}<0.01)$.

\subsection{Comparison of central vs. peripheral effects}

We compared the percentage of variation in key parameters after central or peripheral leptin administration, as well as the degree of insulin response in both groups of leptin-treated rats. The increase in body weight at the end of the study in respect to their controls was higher in peripheral- (19.6\%) than in central-treated rats $(5.7 \%, \mathrm{p}<0.001)$.

Serum leptin levels were similar in both groups of leptin-treated rats (Fig. 1G and 9C), however; glucagon levels in peripheral treatment groups remained unchanged (Fig. 9D), whereas central leptin reduced these levels (Fig. 1D). Serum $\alpha$-MSH showed no differences between after central or peripheral leptin administration, nevertheless; the increment in serum levels after insulin infusion was lower in peripheral leptin group (62\%) than in rats centrally treated $(173 \%, \mathrm{p}<0.01)$.

When we analyzed insulin signaling in the liver, peripheral leptin did not modify activation of IRS1, however; central leptin increased it. The activation of this target after insulin infusion was lower in peripheral leptin-treated rats (18\%) than after central leptin infusion $(37 \%, \mathrm{p}<0.01)$. Phosphorylation of Akt did not change in response to peripheral leptin-treatment and its augment after insulin infusion was lower (16\%) than that observed in central leptin-treated group $(40 \%, p<0.01)$. Finally, the increase in glycogen content in the liver after insulin infusion was inferior in peripheral leptin-treated rats (120\%) than in those centrally treated (485\%, p < 0.001).

\section{Discussion}

Our results suggest that leptin reduces the rise in glycemia induced by increased brain insulin levels by modifying hepatic glucose metabolism. The central insulin induced increase in hepatic glycogen levels, is associated with the activation of insulin signaling in the liver, even though circulating insulin levels are unchanged. Modifications in serum acylated ghrelin, glucagon, leptin and several interleukins could induce some of the observed changes in hepatic metabolism and subsequent modifications in glycemia in response to central insulin administration. Some of the effects on hepatic insulin signaling in response to central leptin administration could be directly attributed to increased serum levels of leptin. However, the changes observed with peripherally infused leptin, reaching similar levels of hyperleptinemia, were not equivalent. Peripherally infused leptin did not modify key hepatic targets that were modified by central leptin infusion, such as pIRS1 and pAkt. Furthermore, the effect of leptin on the response to central insulin 

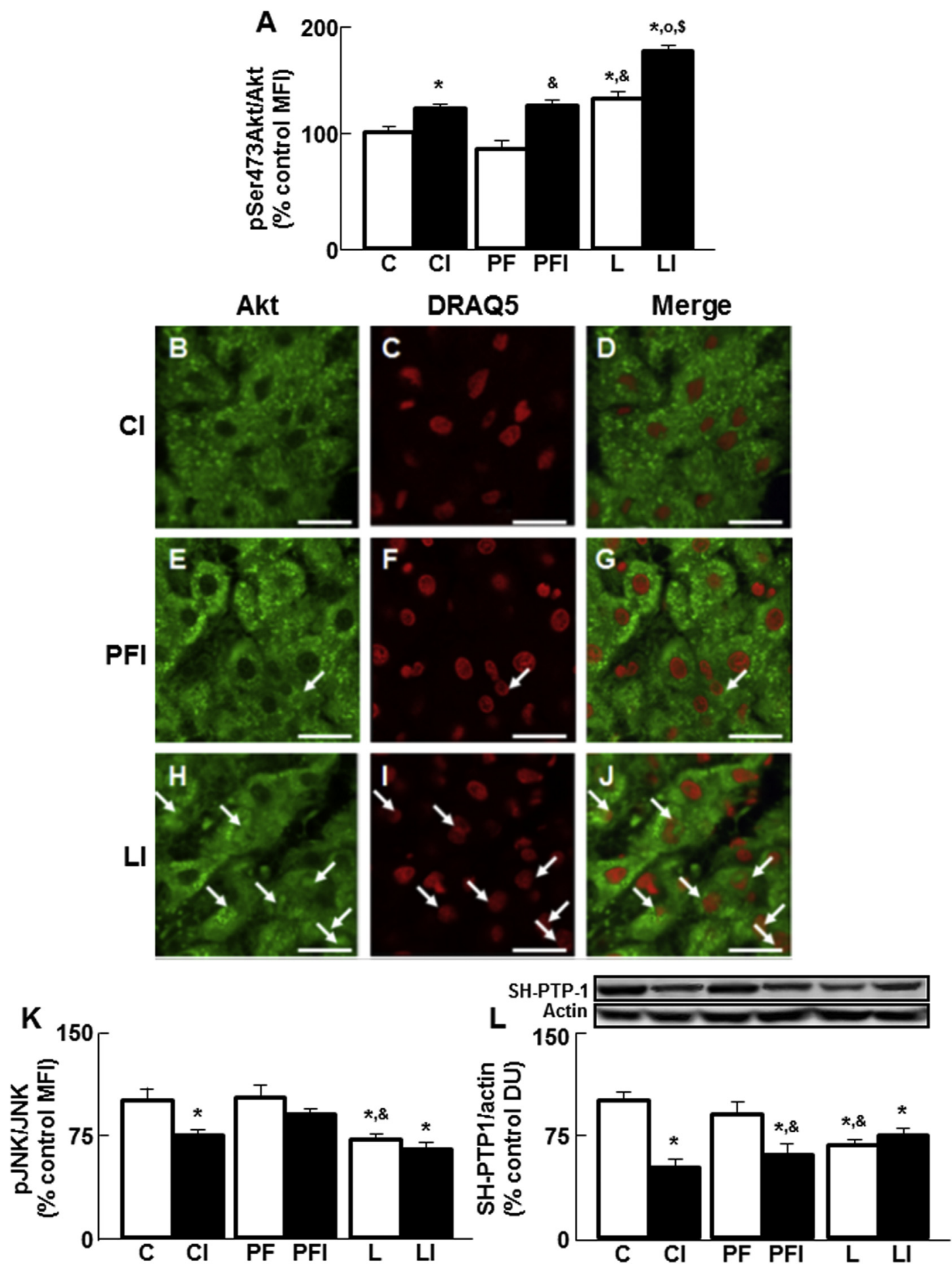

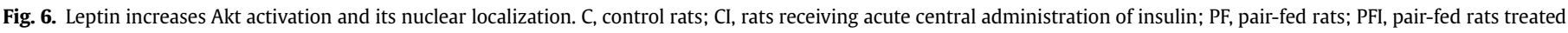

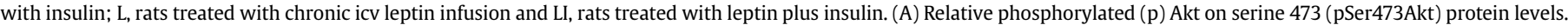

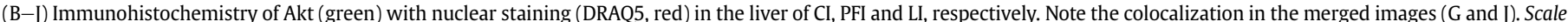

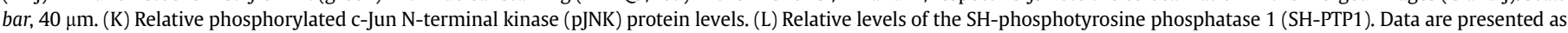

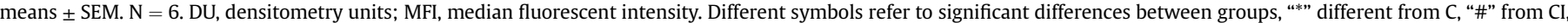
"\&" from PF, "o" from PFI and "\$" from L. Significance: $\mathrm{p}<0.05$ in panels A and $\mathrm{K}$ and $\mathrm{p}<0.01$ in panel L.

was greater in rats infused centrally. This could be due, at least in part, to the fact that centrally injected leptin-animals displayed more dramatic reductions in body weight and adipose tissue than those peripherally infused.

Our findings show that leptin actions are involved in the regulation of glycemia. Central insulin infusion increased serum glucose and leptin reduced this induced rise in glycemia. Moreover, the response in glucose and insulin tolerance tests also suggest that central leptin improves insulin control of glucose levels, as suggested previously (Park et al., 2008). Changes in peripheral hormones after central leptin infusion could also be involved in regulation of glycemia as a rise in central leptin is reported to 

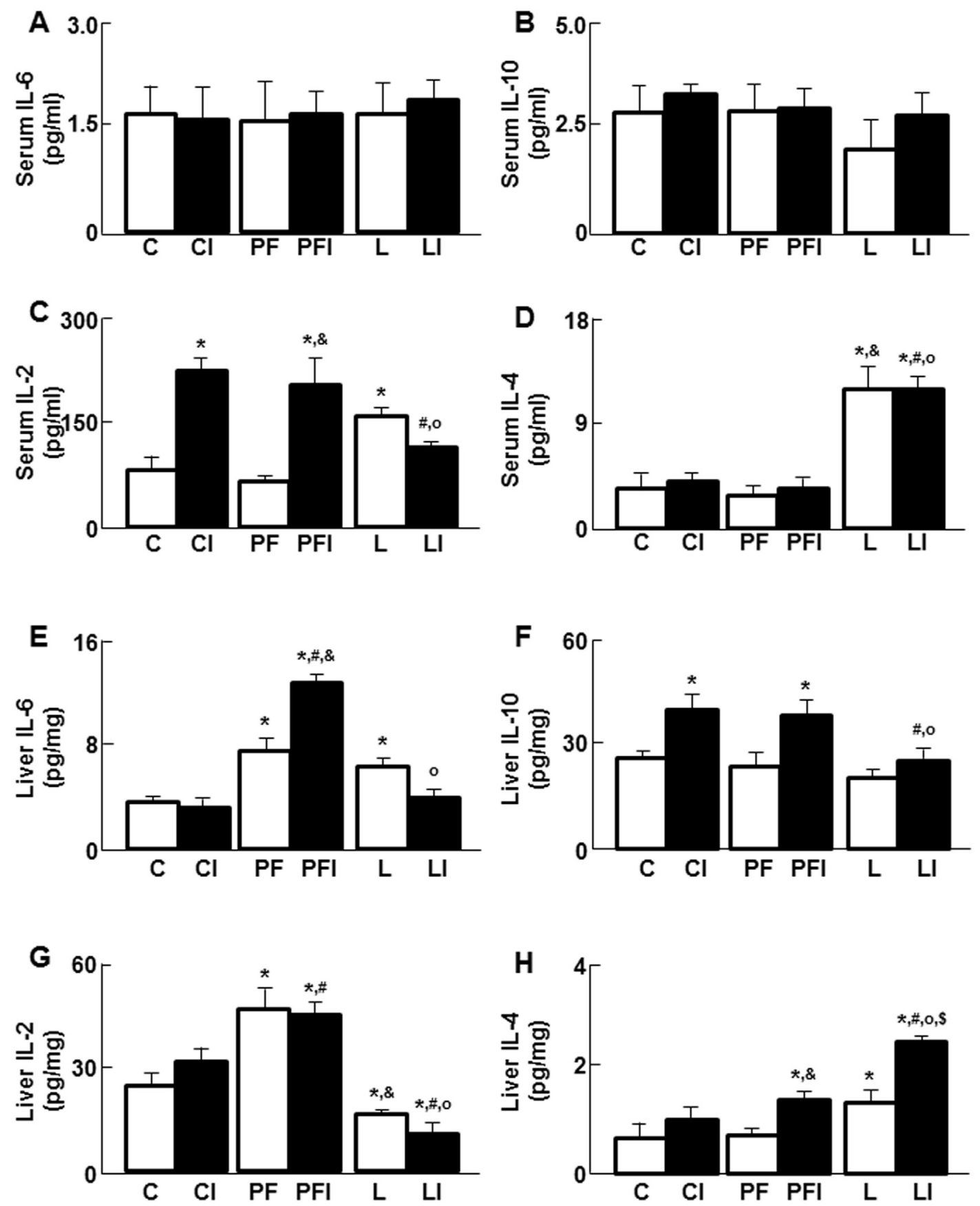

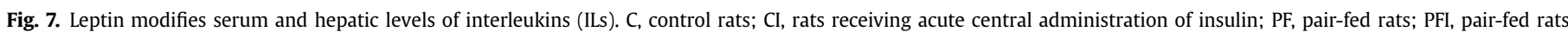

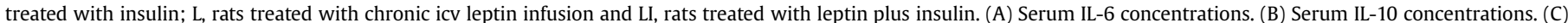

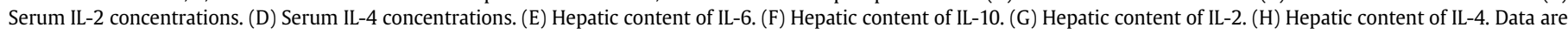

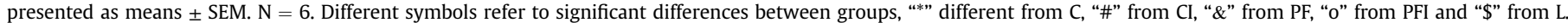
Significance: $\mathrm{p}<0.05$ in panels C, F and G; $\mathrm{p}<0.01$ in panels $\mathrm{E}$ and $\mathrm{H}$ and $\mathrm{p}<0.001$ in panel D.

reverse insulin resistance (Pocai et al., 2005). Most of the effects observed here appear to be independent of leptin-induced changes in food intake as not only is the reduction in glycemia after insulin different in pair-fed and leptin-treated rats, but also the changes in hepatic signaling and glucose metabolism. Accordingly, leptin infusion regulates glycemia independently of food intake (Hidaka et al., 2002). Leptin-treated rats exhibited lower glucagon levels that may be associated with the observed improvement in glycemia control. Indeed, leptin has beneficial effects for treatment of diabetes (Wang et al., 2010) and these effects may be related to inhibition of glucagon (Lee et al., 2014). Finally, leptin infusion provokes hyperleptinemia (Morrison et al., 2001) and although icv leptin contributes to this rise (Maness et al., 1998), increased synthesis in fat indicates that it is at least partially due to increased production. Although the mechanism is not fully understood, infusion of leptin into the brain promotes triiodothyronine production (Cusin et al., 2000), which increases leptin mRNA levels in fat (Ramsay and Richards, 2004). The increase in leptin expression could be related to an increase in insulin sensitivity, as this hormone augments leptin synthesis in fat (Saladin et al., 1995; 
A
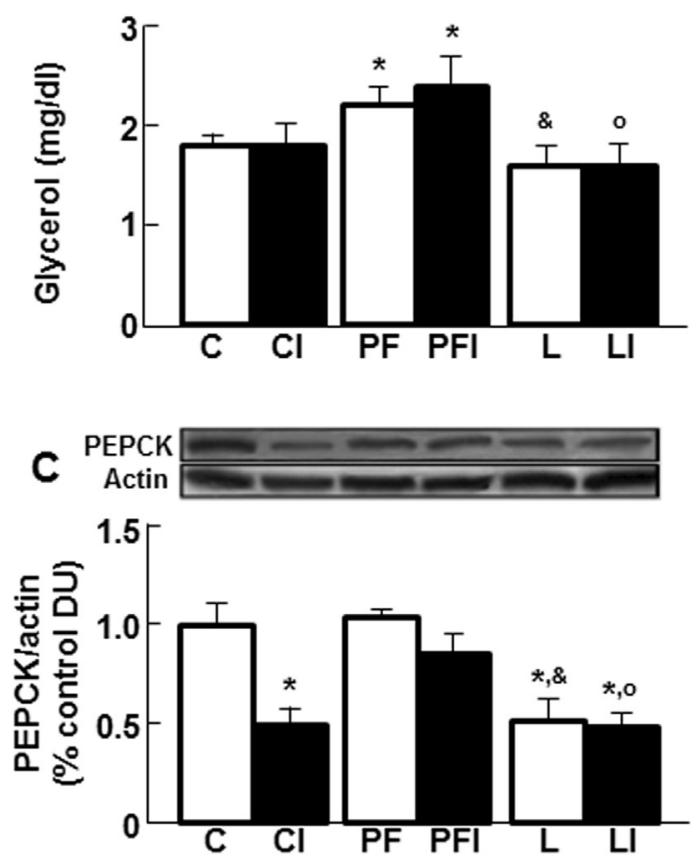

E

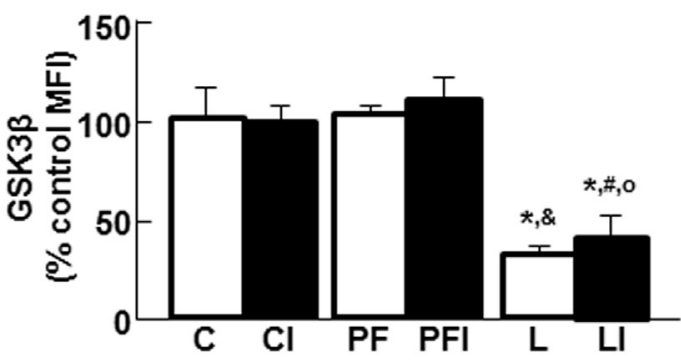

B $\quad$ Actin
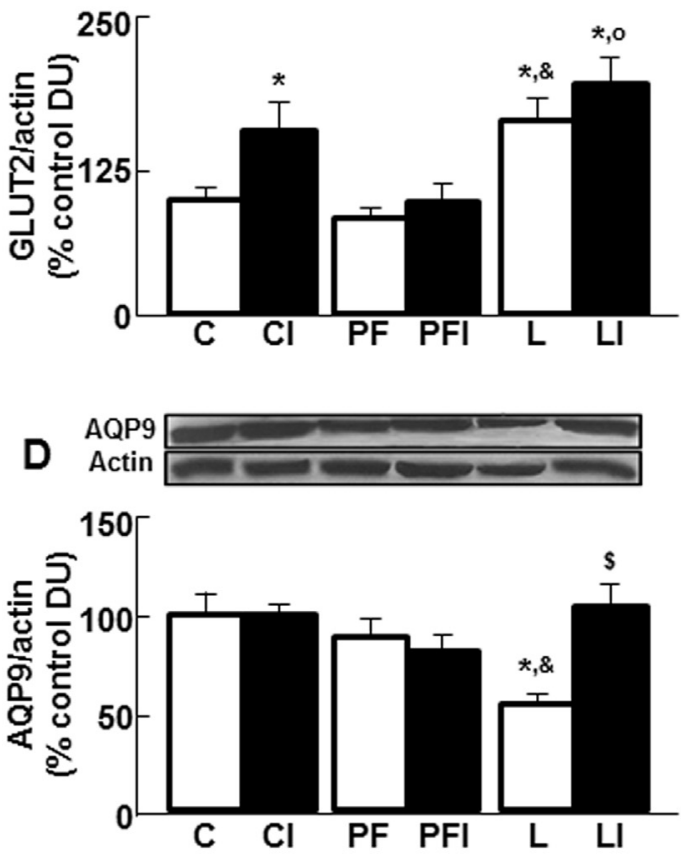

$\mathbf{F}$

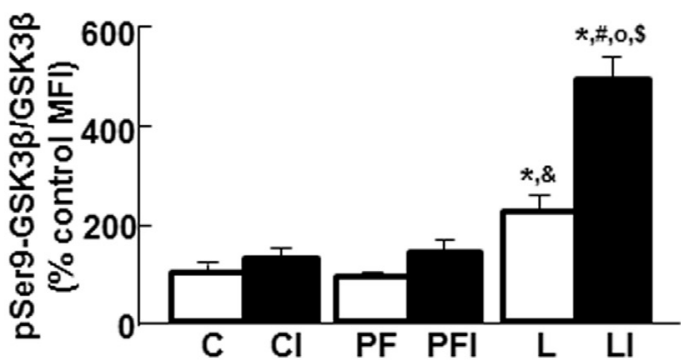

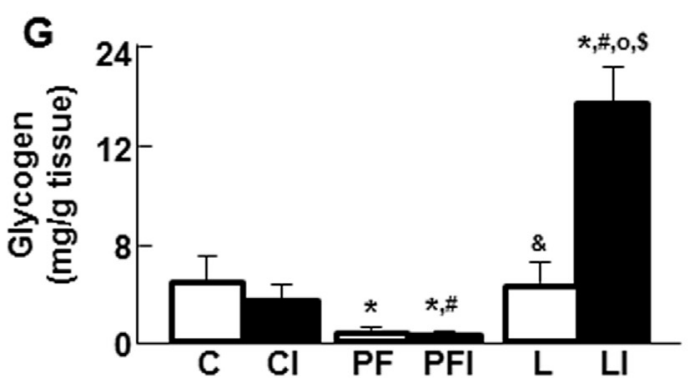

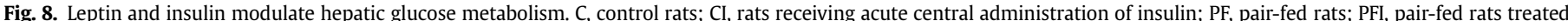

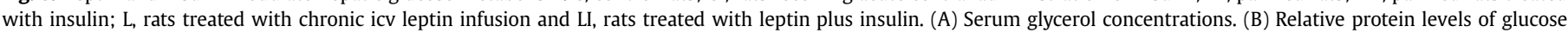

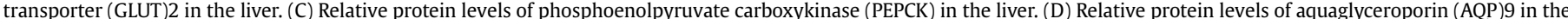

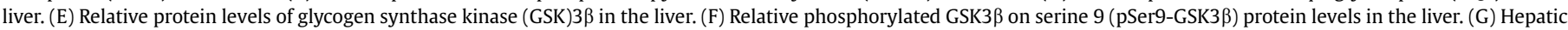

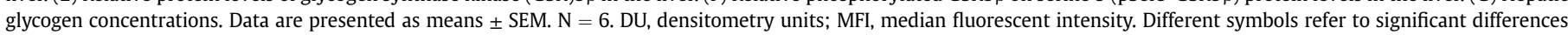

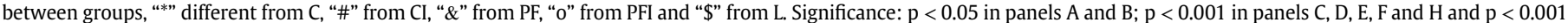
in panel G.

Wabitsch et al., 1996) and its deficiency down-regulates leptin mRNA in adipose tissue (MacDougald et al., 1995). Central leptin infusion has also been demonstrated to increase plasma corticosterone (Van Dijk et al., 1997) that augments leptin in adipose tissue (Fried et al., 2000).

Leptin and insulin activate their signaling pathways in the hypothalamus and increase circulating $\alpha$-MSH levels. In fact, central infusion of both hormones is reported to increase $\alpha$-MSH and reduce weight gain and adiposity (Dhillon et al., 2000) and mutations that inactivate $\alpha$-MSH degradation reduce hepatic PEPCK and improve glucose homeostasis (Jeong et al., 2012). Moreover, a reduction in $\alpha$-MSH production is associated with increased 
A
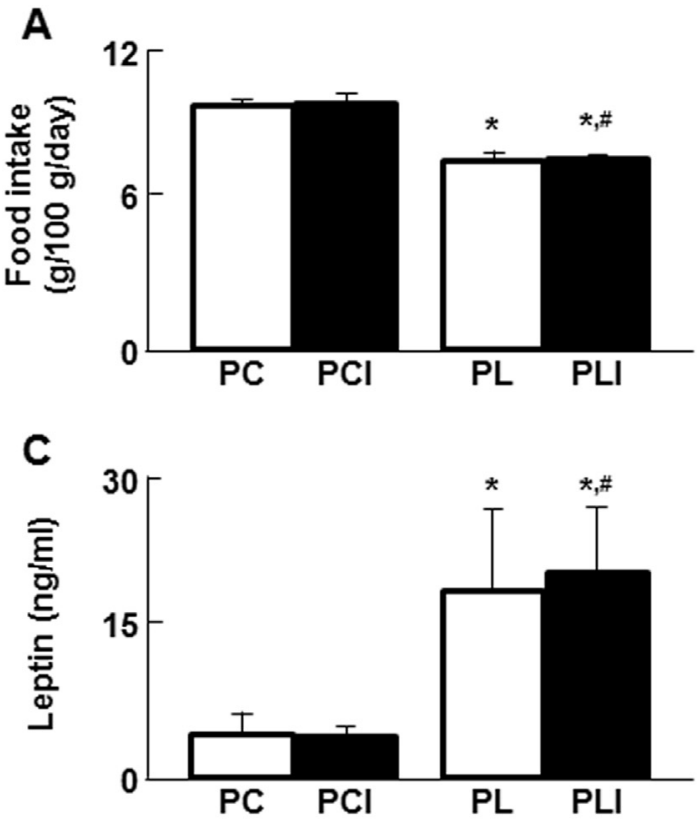
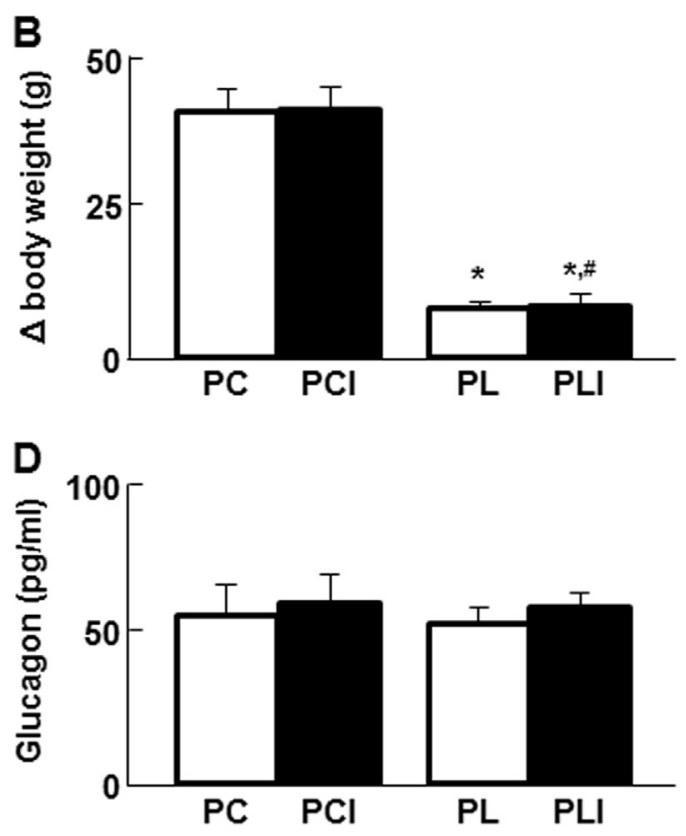
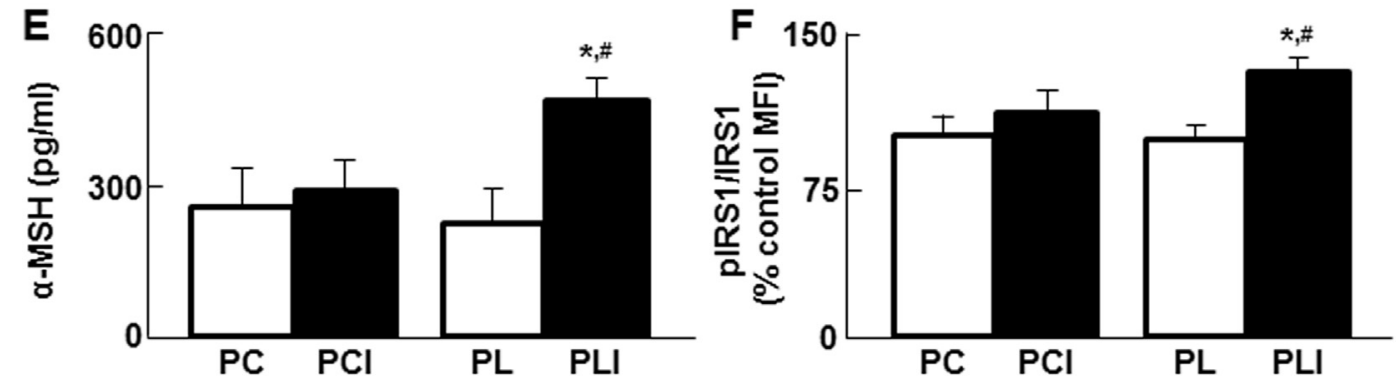

G

H
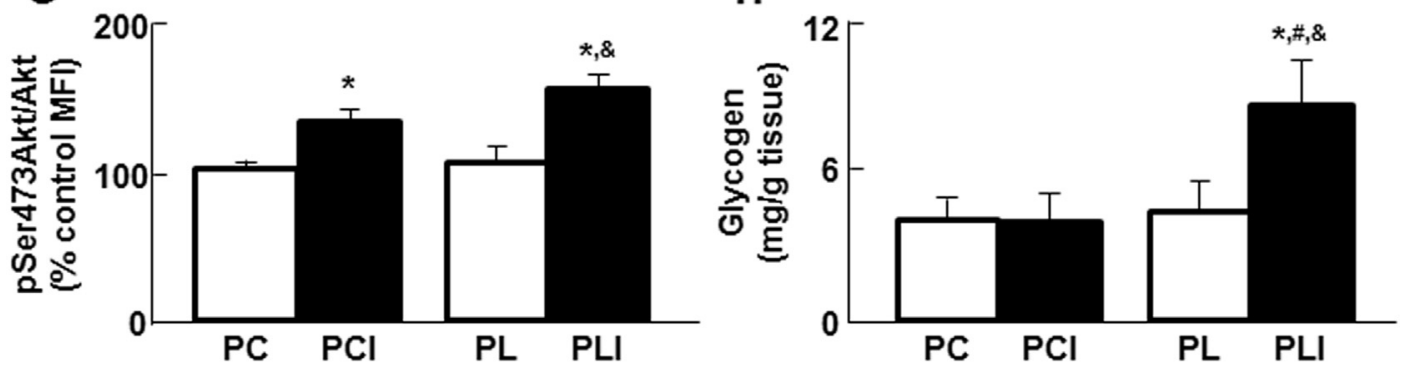

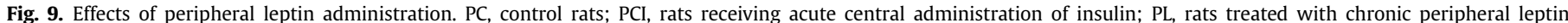

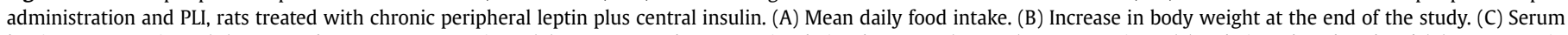

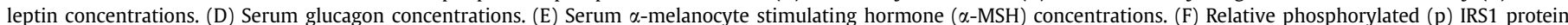

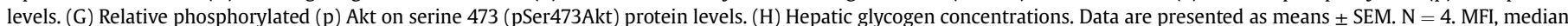

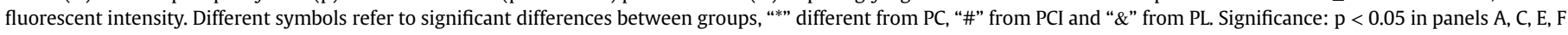
and $\mathrm{G}$ and $\mathrm{p}<0.01$ in panel $\mathrm{B}$.

gluconeogenesis and glucose intolerance (Claret et al., 2011). Thus, our results suggest that activation of central signaling is related with an improvement in the control of glycemia mediated by an increase in circulating $\alpha$-MSH levels.

Our findings suggest that hepatic activation of leptin and insulin signaling pathways plays an important role in the control of glycemia through augmenting utilization of glucose by the liver for glycogen synthesis. We show that insulin was unable to induce SOCS3 after leptin infusion and this resulted in reduced SOCS3 binding to IR $\beta$, allowing IR $\beta$ to interact with IRS1, which would potentiate insulin signaling (Zolotnik et al., 2012). We also found an increase in pIRS1 levels with subsequent Akt activation. These data suggest that reduction of SOCS3 may play a protective role against insulin resistance and glucose intolerance (Huynh et al., 2010). Lower JNK activation in leptin-treated rats might explain the rise in IRS1 levels, as JNK degrades IRS1 and reduces hepatic insulin signaling (Taniguchi et al., 2005), worsening glucose homeostasis. The reduction in hepatic SH-PTP1 levels in leptin-treated rats could also be related to improved control of serum glucose as SH-PTP1 prevents insulin-stimulated Akt activation through p85 
inactivation (Lodeiro et al., 2011) and impairs glycemia control (Drapeau et al., 2013). Changes in hepatic insulin signaling after its central infusion seem to be associated with variations in circulating hormones, such as $\alpha$-MSH (Jeong et al., 2012). Indeed, treatment with melanocortin receptor agonists augments insulin sensitivity in the liver (Kumar et al., 2009). In addition, the reduced rise in ghrelin after central insulin infusion in leptin-treated rats could be an additional factor that maintains insulin sensitivity (Longo et al., 2011; Neuman et al., 2014). Additionally, it has been reported that STAT3 activation in the hypothalamus plays a key role in glucose homeostasis and insulin sensitivity in the liver (Wu et al., 2014) and we have STAT3 phosphorylation to increase after insulin infusion in leptin-treated rats.

Cumulating evidence indicates that a reduction in adiposity enhances insulin sensitivity. In this regard, leptin decreases fat mass and improves hepatic insulin action, inhibiting glucose synthesis and augmenting its uptake (Barzilai et al., 1997). Moreover, in models of type 2 diabetes with augmented adiposity, leptin reduces fat stores, improving lipid metabolism independently of food intake with a concomitant enhancement of insulin sensitivity (Kusakabe et al., 2009; Sakai et al., 2014). Inflammation is also associated with insulin resistance. The lower adiposity found in leptin-treated rats could also change systemic metabolic signals such as interleukin levels, thus modifying insulin sensitivity (Beretta et al., 2002; Cettour-Rose et al., 2005). Hepatic IL-2 was reduced after leptin treatment, concordant with the relationship between lower JNK activity and IL-2 levels and improved glycemia (Jiang et al. 2013). Augmented IL-4 after leptin treatment may be a mechanism by which Akt is activated, as IRS1 is phosphorylated by this interleukin (Xiao et al., 2002). However, insulin resistance is associated with adiposity, while weight loss enhances insulin sensitivity with a simultaneous decrease in proinflammatory cytokines (German et al., 2009). Endoplasmic reticulum (ER) stress is a potential contributor to the development of insulin resistance and hepatic inflammation (Brenner et al., 2013). Leptin inhibits ER stress proteins (Xiong et al., 2014) and attenuation of ER stress improves glucose homeostasis and insulin signaling in liver (Latreille et al., 2011). In addition, an increase in ER stress is linked to stimulation of gluconeogenesis (Wang et al., 2009). Our results suggest that the decline in proinflammatory cytokines and the reduction of PEPCK, improvement of insulin signaling and glycemia after leptin infusion might be mediated by a reduction in ER stress.

Our findings suggest that leptin enhances the effect of central insulin on hepatic glucose metabolism. Leptin increases hepatic GLUT2 levels, which could indicate an increased influx of glucose into the liver (Sole and Srinivasan, 2012). Insulin activates Akt to phosphorylate GSK3 $\beta$ on Ser9 causing an inhibitory effect (Cross et al., 1995) and rising glycogen levels. The increase in glycogen after insulin may act as a "physiological buffer" to maintain glycemia in an adequate range in leptin-treated rats. Moreover, nuclear localization of Akt in the leptin-treated rats may also potentiate insulin's effects, as translocation of Akt into the nucleus can exclude forkhead box 01, a transcription factor for PEPCK (Oh et al., 2013), thus possibly explaining the lower levels of this gluconeogenic enzyme.

The results obtained with chronic peripheral leptin administration indicate that some of the effects of central leptin infusion cannot be attributed to hyperleptinemia. Although serum levels were similar after both treatments, central leptin produced changes in several hormones related to increased insulin sensitivity and activated hepatic signaling, whereas the peripheral treatment did not modify these parameters equally. In addition, the effects of central leptin infusion on reduction in food intake, body weight and adipose tissue were more potent than peripheral administration, as previously reported (Suzuki et al., 2010; Penn et al., 2006). Central leptin administration was also more potent in modulating hepatic insulin signaling. Finally, it has been reported that the effects of peripheral or central administration on hepatic leptin signaling gene expression and metabolism differs (Sharma et al., 2010) and the leptin-mediated increase in insulin sensitivity seems not to be due to changes in inflammatory markers after peripheral administration (Cummings et al., 2011).

Several caveats should be taken into consideration when evaluating these results. First, a rise in glycemia after central insulin infusion is controversial. Although most reports indicate that central insulin decreases or has no effect on glycemia, there are studies demonstrating an increase in glycemia (Ajaya and Haranath, 1982; Yavropoulou et al., 2009; Burgos-Ramos et al., 2011). This effect could be related to the role of the autonomous system in conducting brain actions of insulin to the periphery contributing to the central anorexigenic effects of insulin (Xu et al., 2005). Likewise, the beneficial action of central leptin infusion on the activation of hepatic insulin signaling may involve a vagal mechanism. In this regard, leptin increases sympathetic outflow independently of feeding and regulates serum metabolites by affecting hepatic processes (Miyamoto et al., 2012) and controls insulin secretion, improving glucose tolerance through sympathetic nerve activation (Park et al., 2010). Nevertheless, these mechanisms are not totally clear. Hepatic vagal and non-vagal mechanisms on improvement of peripheral insulin sensitivity after central leptin infusion have been reported to occur simultaneously (Li et al., 2011) and leptin modulates hepatic glucose fluxes through central melanocortindependent and independent pathways in order to inhibit gluconeogenesis (Gutiérrez-Juárez et al., 2004). In addition, the response of leptin reported here may be considered pharmacological, although similar dosages exert effects on food intake and energy homeostasis (Friedman and Halaas, 1998) and reproduce physiological effects (Hidaka et al., 2002; Sahu, 2008). Finally, the reduction in STAT3 activation in the liver in response to leptin may be unexpected and related to previous reported effects of this treatment. In this regard, although icv leptin during the same period reduced weight gain, the difference in weight gain during the last days was not significant, suggesting that some animals may be developing resistant to the treatment (García-Cáceres et al., 2011). Thus, it is possible that there is a reduction in leptin sensitivity in response to the chronic treatment, although this requires further investigation. In addition, icv leptin activates hepatic outflow and requires PI3K, but not STAT3 (Tanida et al., 2015). Moreover, it has been shown that hepatic inhibition of the leptin signaling pathway improves insulin response (Kim et al., 2008; Huynh et al., 2010; Li et al., 2014).

\section{Conclusions}

As summarized in Fig. 10, our results suggest that leptin is involved in the regulation of glycemia through modulation of the central and hepatic response to central insulin. Our results indicate a possible important role of the decreased association of SOCS3 to the insulin receptor in response to leptin, which modulates the response to an increase in insulin. In leptin treated animals the hepatic response to central insulin is modified, with key molecules involved in the hepatic uptake of glucose for glycogen synthesis being increased and reducing gluconeogenesis. These findings suggest that pharmacological intervention of leptin and insulin signaling may be a strategy for controlling glycemia.

\section{Disclosure statement}

The authors have nothing to disclose. 


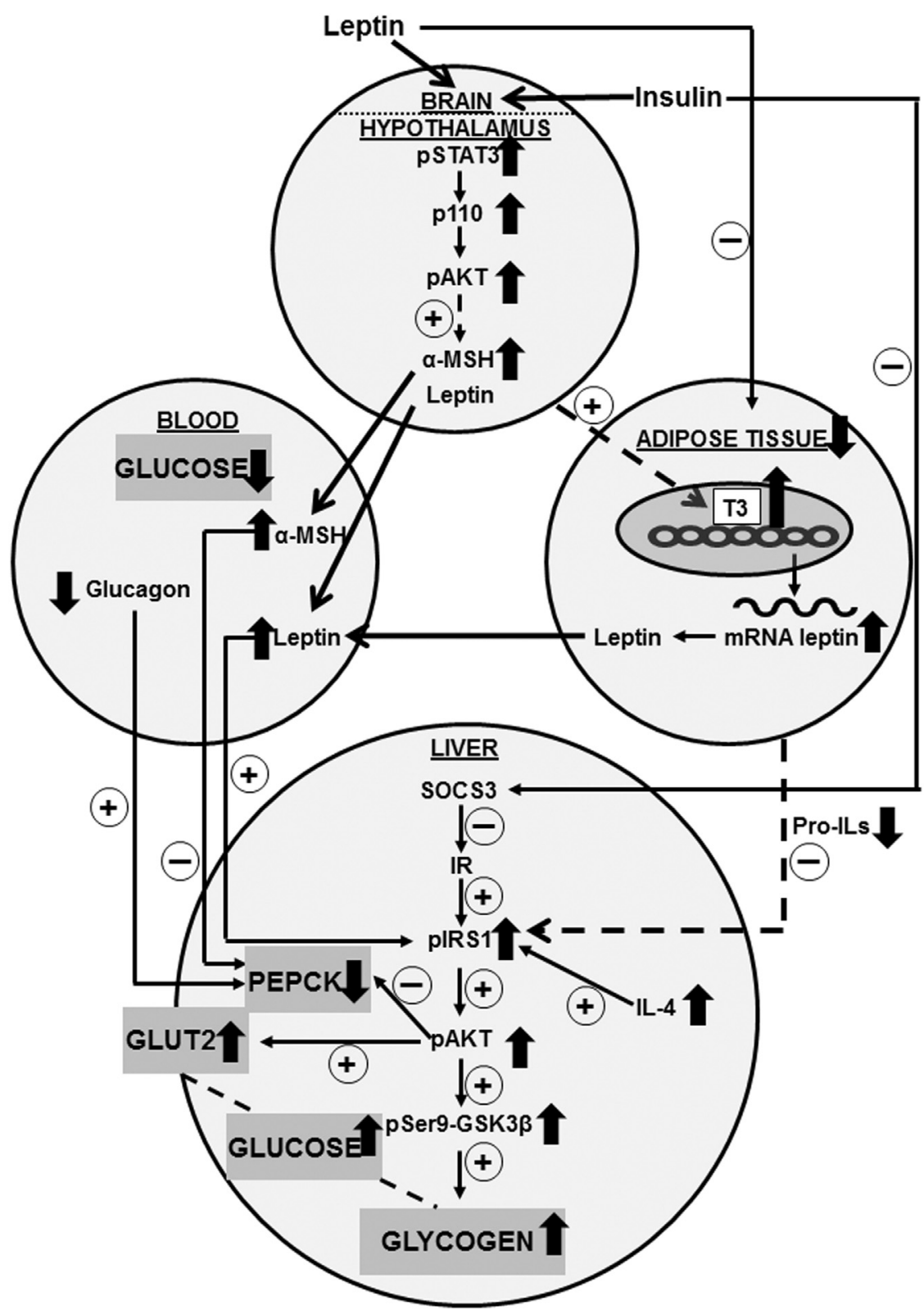

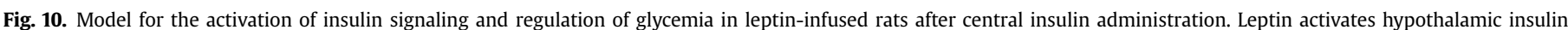

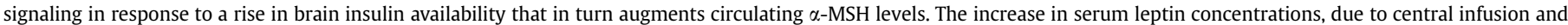

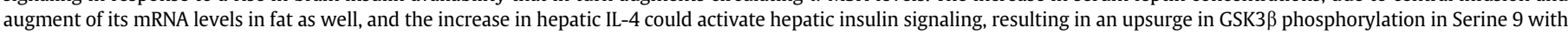

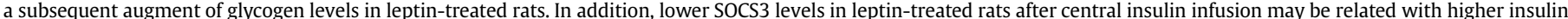

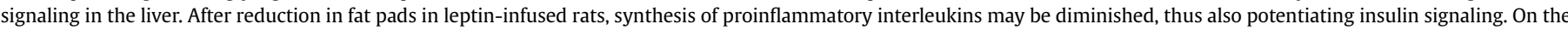

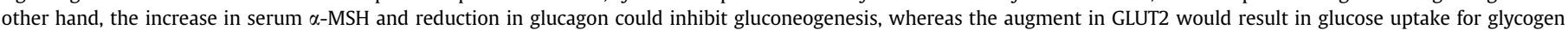

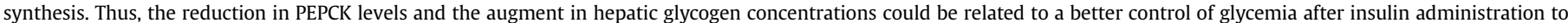

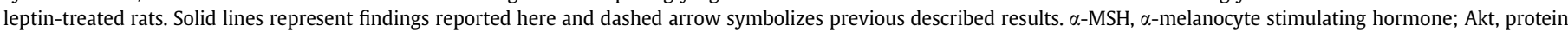

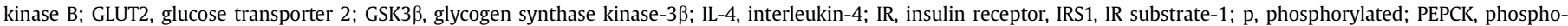
enolpyruvate carboxykinase; SOCS3, suppressor of cytokine signaling 3; STAT3, signal transducer and activator of transcription factor 3; T3, triiodothyronine.

\section{Acknowledgments}

We greatly thank Francisca Díaz for excellent technical assistance. This work was supported by the Spanish Ministry of Science and Innovation with the help of European FEDER funding (FIS PI10/ 01677, FIS PI12/00515, FIS PI13/01430 and FIS PI13/02195), Ministerio de Economía y Competitividad (BFU 2014-51836-C2-2-R), the Network Center for Biomedical Research on Obesity and Nutrition (CIBEROBN) Instituto Carlos III and Fundación Endocrinología y Nutrición. S.C. is supported by CIBEROBN.

\section{References}

Ajaya, B., Haranath, P.S., 1982. Effects of insulin administered into cerebrospinal fluid spaces on blood glucose in unanaesthetized and anaesthetized dogs. Indian J. Med. Res. 75, 607-615.

Banks, W.A., Lebel, C.R., 2002. Strategies for the delivery of leptin to the CNS. J. Drug Target 10, 297-308. http://dx.doi.org/10.1080/10611860290031895.

Bartell, S.M., Rayalam, S., Ambati, S., Gaddam, D.R., Hartzell, D.L., Hamrick, M. She, J.X., Della-Fera, M.A., Baile, C.A., 2011. Central (ICV) leptin injection increases bone formation, bone mineral density, muscle mass, serum IGF-1, and the expression of osteogenic genes in leptin-deficient ob/ob mice. J. Bone Min. Res. 26, 1710-1720. http://dx.doi.org/10.1002/jbmr.406.

Barzilai, N., Wang, J., Massilon, D., Vuguin, P., Hawkins, M., Rossetti, L., 1997. Leptin 
selectively decreases visceral adiposity and enhances insulin action. J. Clin. Invest. 100, 3105-3110. http://dx.doi.org/10.1172/JCI119865.

Beretta, E., Dube, M.G., Kalra, P.S., Kalra, S.P., 2002. Long-term suppression of weight gain, adiposity, and serum insulin by central leptin gene therapy in prepubertal rats: effects on serum ghrelin and appetite-regulating genes. Pediatr. Res. 52, 189-198. http://dx.doi.org/10.1203/00006450-200208000-00010.

Brenner, C., Galluzzi, L., Kepp, O., Kroemer, G., 2013. Decoding cell death signals in liver inflammation. J. Hepatol. 59, 583-594. http://dx.doi.org/10.1016/ j.jhep.2013.03.033.

Burgos-Ramos, E., Chowen, J.A., Arilla-Ferreiro, E., Canelles, S., Argente, J., Barrios, V 2011. Chronic central leptin infusion modifies the response to acute central insulin injection by reducing the interaction of the insulin receptor with IRS2 and increasing its association with SOCS3. J. Neurochem. 117, 175-185. http:/ dx.doi.org/10.1111/j.1471-4159.2011.07191.x.

Cettour-Rose, P., Theander-Carrillo, C., Asensio, C., Klein, M., Visser, T.J., Burger, A.G. Meier, C.A., Rohner-Jeanrenaud, F., 2005. Hypothyroidism in rats decreases peripheral glucose utilisation, a defect partially corrected by central leptin infusion. Diabetologia 48, 624-633. http://dx.doi.org/10.1007/s00125-0051696-4.

Claret, M., Smith, M.A., Knauf, C., Al-Qassab, H., Woods, A., Heslegrave, A., Piipari, K., Emmanuel, J.J., Colom, A., Valet, P., Cani, P.D., Begum, G., White, A., Mucket, P., Peters, M., Mizuno, K., Batterham, R.L., Giese, K.P., Ashworth, A., Burcelin, R., Ashford, M.L., Carling, D., Withers, D.J., 2011. Deletion of Lkb1 in proopiomelanocortin neurons impairs peripheral glucose homeostasis in mice. Diabetes 60, 735-745. http://dx.doi.org/10.2337/db10-1055.

Crépin, D., Benomar, Y., Riffault, L., Amine, H., Gertler, A., Taouis, M., 2014. The overexpression of miR-200a in the hypothalamus of ob/ob mice is linked to leptin and insulin signaling impairment. Mol. Cell Endocrinol. 384, 1-11. http:// dx.doi.org/10.1016/j.mce.2013.12.016.

Cross, D.A., Alessi, D.R., Cohen, P., Andjelkovich, M., Hemmings, B.A., 1995. Inhibition of glycogen synthase kinase- 3 by insulin mediated by protein kinase B. Nature 378, 785-789. http://dx.doi.org/10.1038/378785a0.

Cummings, B.P., Bettaieb, A., Graham, J.L., Stanhope, K.L., Dill, R., Morton, G.J. Haj, F.G., Havel, P.J., 2011. Subcutaneous administration of leptin normalizes fasting plasma glucose in obese type 2 diabetic UCD-T2DM rats. Proc. Natl. Acad. Sci. U. S. A. 108, 14670-14675. http://dx.doi.org/10.1073/pnas.1107163108.

Cusin, I., Rouru, J., Visser, T., Burger, A.G., Rohner-Jeanrenaud, F., 2000. Involvement of thyroid hormones in the effect of intracerebroventricular leptin infusion on uncoupling protein-3 expression in rat muscle. Diabetes 49, 1101-1105. http:// dx.doi.org/10.2337/diabetes.49.7.1101.

Dali-Youcef, N., Mecili, M., Ricci, R., Andrès, E., 2013. Metabolic inflammation: connecting obesity and insulin resistance. Ann. Med. 45, 242-253. http:// dx.doi.org/10.3109/07853890.2012.705015.

De Vries, E.M., Eggels, L., van Beeren, H.C., Ackermans, M.T., Kalsbeek, A., Fliers, E., Boelen, A., 2014. Fasting-induced changes in hepatic thyroid hormone metabolism in male rats are independent of autonomic nervous input to the liver. Endocrinology 155, 5033-5041. http://dx.doi.org/10.1210/en.2014-1608.

Dhillon, H., Ge, Y., Minter, R.M., Prima, V., Moldawer, L.L., Muzyczka, N., Zolotukhin, S., Kalra, P.S., Kalra, S.P., 2000. Long-term differential modulation of genes encoding orexigenic and anorexigenic peptides by leptin delivered by rAAV vector in ob/ob mice. Relationship with body weight change. Regul. Pept. 92, 97-105. http://dx.doi.org/10.1016/S0167-0115(00)00155-5.

Drapeau, N., Lizotte, F., Denhez, B., Guay, A., Kennedy, C.R., Geraldes, P., 2013. Expression of SHP-1 induced by hyperglycemia prevents insulin actions in podocytes. Am. J. Physiol. Endocrinol. Metab. 304, E1188-E1198. http:/ dx.doi.org/10.1152/ajpendo.00560.2012.

D'souza, A.M., Asadi, A., Johnson, J.D., Covey, S.D., Kieffer, T.J., 2014. Leptin deficiency in rats results in hyperinsulinemia and impaired glucose homeostasis. Endocrinology 155, 1268-1279. http://dx.doi.org/10.1210/en.2013-1523.

Fried, S.K., Ricci, M.R., Russell, C.D., Laferrère, B., 2000. Regulation of leptin production in humans. J. Nutr. 130, 3127S-3131S.

Friedman, J.M., Halaas, J.L., 1998. Leptin and the regulation of body weight in mammals. Nature 395, 763-770. http://dx.doi.org/10.1038/27376.

García-Cáceres, C., Fuente-Martín, E., Burgos-Ramos, E., Granado, M., Frago, L.M., Barrios, V., Horvath, T., Argente, J., Chowen, J.A., 2011. Differential acute and chronic effects of leptin on hypothalamic astrocyte morphology and synaptic protein levels. Endocrinology 152, 1809-1818. http://dx.doi.org/10.1210/ en.2010-1252.

German, A.J., Hervera, M., Hunter, L., Holden, S.L., Morris, P.J., Biourge, V Trayhurn, P., 2009. Improvement in insulin resistance and reduction in plasma inflammatory adipokines after weight loss in obese dogs. Domest. Anim. Endocrinol. 37, 214-226. http://dx.doi.org/10.1016/j.domaniend.2009.07.001.

Gutiérrez-Juárez, R., Obici, S., Rossetti, L., 2004. Melanocortin-independent effects of leptin on hepatic glucose fluxes. J. Biol. Chem. 279, 49704-49715. http:// dx.doi.org/10.1074/jbc.M408665200.

Havrankova, J., Schmechel, D., Roth, J., Brownstein, M., 1978. Identification of insulin in rat brain. Proc. Natl. Acad. Sci. U. S. A. 75, 5737-5741. PMCID: PMC393044.

Hidaka, S., Yoshimatsu, H., Kondou, S., Tsuruta, Y., Oka, K., Noguchi, H., Okamoto, K. Sakino, H., Teshima, Y., Okeda, T., Sakata, T., 2002. Chronic central leptin infusion restores hyperglycemia independent of food intake and insulin level in streptozotocin-induced diabetic rats. FASEB J. 16, 509-518. http://dx.doi.org/ 10.1096/fj.01-0164com.

Huynh, F.K., Levi, J., Denroche, H.C., Gray, S.L., Voshol, P.J., Neumann, U.H., Speck, M. Chua, S.C., Covey, S.D., Kieffer, T.J., 2010. Disruption of hepatic leptin signaling protects mice from age- and diet-related glucose intolerance. Diabetes 59,
3032-3040. http://dx.doi.org/10.2337/db10-0074.

Jeong, J.K., Szabo, G., Raso, G.M., Meli, R., Diano, S., 2012. Deletion of prolyl carboxypeptidase attenuates the metabolic effects of diet-induced obesity. Am. J. Physiol. Endocrinol. Metab. 302, E1502-E1510. http://dx.doi.org/10.1152/ ajpendo.00544.2011.

Jiang, M., Wang, C., Meng, Q., Li, F., Li, K., Luo, L., Sun, C., 2013. Cyclosporin A attenuates weight gain and improves glucose tolerance in diet-induced obese mice. Mol. Cell Endocrinol. 370, 96-102. http://dx.doi.org/10.1016/ j.mce.2013.02.018.

Jiao, P., Feng, B., Li, Y., He, Q., Xu, H., 2013. Hepatic ERK activity plays a role in energy metabolism. Mol. Cell Endocrinol. 375, 157-166. http://dx.doi.org/10.1016/ j.mce.2013.05.021.

Kellerer, M., Koch, M., Metzinger, E., Mushack, J., Capp, E., Häring, H.U., 1997. Leptin activates PI-3 kinase in C2C12 myotubes via janus kinase-2 (JAK-2) and insulin receptor substrate-2 (IRS-2) dependent pathways. Diabetologia 40, 1358-1362. http://dx.doi.org/10.1007/s001250050832.

Kim, J.H., Kim, J.E., Liu, H.Y., Cao, W., Chen, J., 2008. Regulation of interleukin-6induced hepatic insulin resistance by mammalian target of rapamycin through the STAT3-SOCS3 pathway. J. Biol. Chem. 283, 708-715. http:// dx.doi.org/10.1074/jbc.M708568200.

Kulyté, A., Belarbi, Y., Lorente-Cebrián, S., Bambace, C., Arner, E., Daub, C.O., Hedén, P., Rydén, M., Mejhert, N., Arner, P., 2014. Additive effects of miRNAs and transcription factors on CCL2 production in human white adipose tissue. Diabetes 63, 1248-1258. http://dx.doi.org/10.2337/db13-0702.

Kumar, K.G., Sutton, G.M., Dong, J.Z., Roubert, P., Plas, P., Halem, H.A., Culler, M.D., Yang, H., Dixit, V.D., Butler, A.A., 2009. Analysis of the therapeutic functions of novel melanocortin receptor agonists in MC3R- and MC4R-deficient C57BL/6J mice. Peptides 30, 1892-1900. http://dx.doi.org/10.1016/j.peptides.2009.07.012.

Kusakabe, T., Tanioka, H., Ebihara, K., Hirata, M., Miyamoto, L., Miyanaga, F., Hige, H., Aotani, D., Fujisawa, T., Masuzaki, H., Hosoda, K., Nakao, K., 2009. Beneficial effects of leptin on glycaemic and lipid control in a mouse model of type 2 diabetes with increased adiposity induced by streptozotocin and a high-fat diet. Diabetologia 52, 675-683. http://dx.doi.org/10.1007/s00125-009-1258-2.

Latreille, M., Laberge, M.K., Bourret, G., Yamani, L., Larose, L., 2011. Deletion of Nck1 attenuates hepatic ER stress signaling and improves glucose tolerance and insulin signaling in liver of obese mice. Am. J. Physiol. Endocrinol. Metab. 300, E423-E434. http://dx.doi.org/10.1152/ajpendo.00088.2010.

Lee, Y., Berglund, E.D., Yu, X., Wang, M.Y., Evans, M.R., Scherer, P.E., Holland, W.L., Charron, M.J., Roth, M.G., Unger, R.H., 2014. Hyperglycemia in rodent models of type 2 diabetes requires insulin-resistant alpha cells. Proc. Natl. Acad. Sci. U. S. A. 111, 13217-13222. http://dx.doi.org/10.1073/pnas.1409638111.

Li, H., Lee, J., He, C., Zou, M.H., Xie, Z., 2014. Suppression of the mTORC1/STAT3/ Notch1 pathway by activated AMPK prevents hepatic insulin resistance induced by excess amino acids. Am. J. Physiol. Endocrinol. Metab. 306, E197-E209. http://dx.doi.org/10.1152/ajpendo.00202.2013.

Li, X., Wu, X., Camacho, R., Schwartz, G.J., LeRoith, D., 2011. Intracerebroventricular leptin infusion improves glucose homeostasis in lean type 2 diabetic MKR mice via hepatic vagal and non-vagal mechanisms. PLoS One 6, e17058. http:// dx.doi.org/10.1371/journal.pone.0017058.

Lodeiro, M., Alén, B.O., Mosteiro, C.S., Beiroa, D., Nogueiras, R., Theodoropoulou, M., Pardo, M., Gallego, R., Pazos, Y., Casanueva, F.F., Camiña, J.P., 2011. The SHP-1 protein tyrosine phosphatase negatively modulates Akt signaling in the ghrelin/GHSR1a system. Mol. Biol. Cell 22, 4182-4191. http://dx.doi.org/10.1091/ mbc.E11-04-0373.

Longo, K.A., Govek, E.K., Nolan, A., McDonagh, T., Charoenthongtrakul, S., Giuliana, D.J., Morgan, K., Hixon, J., Zhou, C., Kelder, B., Kopchick, J.J., Saunders, J.O., Navia, M.A., Curtis, R., DiStefano, P.S., Geddes, B.J., 2011. Pharmacologic inhibition of ghrelin receptor signaling is insulin sparing and promotes insulin sensitivity. J. Pharmacol. Exp. Ther. 339, 115-124. http:// dx.doi.org/10.1124/jpet.111.183764.

MacDougald, O.A., Hwang, C.S., Fan, H., Lane, M.D., 1995. Regulated expression of the obese gene product (leptin) in white adipose tissue and 3T3-L1 adipocytes. Proc. Natl. Acad. Sci. U. S. A. 92, 9034-9037. PMCID: PMC40918.

Maness, L.M., Kastin, A.J., Farrell, C.L., Banks, W.A., 1998. Fate of leptin after intracerebroventricular injection into the mouse brain. Endocrinology 139, 4556-4562.

Miller, B.H., Olson, S.L., Levine, J.E., Turek, F.W., Horton, T.H., Takahashi, J.S., 2006. Vasopressin regulation of the proestrous luteinizing hormone surge in wildtype and clock mutant mice. Biol. Reprod. 75, 778-784. http://dx.doi.org/ 10.1095/biolreprod.106.052845.

Miyamoto, L., Ebihara, K., Kusakabe, T., Aotani, D., Yamamoto-Kataoka, S., Sakai, T., Aizawa-Abe, M., Yamamoto, Y., Fujikura, J., Hayashi, T., Hosoda, K., Nakao, K., 2012. Leptin activates hepatic 5'-AMP-activated protein kinase through sympathetic nervous system and $\alpha 1$-adrenergic receptor: a potential mechanism for improvement of fatty liver in lipodystrophy by leptin. J. Biol. Chem. 287, 40441-40447. http://dx.doi.org/10.1074/jbc.M112.384545.

Morrison, C.D., Daniel, J.A., Holmberg, B.J., Djiane, J., Raver, N., Gertler, A., Keisler, D.H., 2001. Central infusion of leptin into well-fed and undernourished ewe lambs: effects on feed intake and serum concentrations of growth hormone and luteinizing hormone. J. Endocrinol. 168, 317-324. http://dx.doi.org/ $10.1677 /$ joe.0.1680317.

Ndisang, J.F., Lane, N., Syed, N., Jadhav, A., 2010. Up-regulating the heme oxygenase system with hemin improves insulin sensitivity and glucose metabolism in adult spontaneously hypertensive rats. Endocrinology 151, 549-560. http:// dx.doi.org/10.1210/en.2009-0471. 
Neuman, M.G., Cohen, L.B., Nanau, R.M., 2014. Biomarkers in nonalcoholic fatty liver disease. Can. J. Gastroenterol. Hepatol. 28, 607-618. PMCID: PMC4277175.

Oh, K.J., Han, H.S., Kim, M.J., Koo, S.H., 2013. CREB and FoxO1: two transcription factors for the regulation of hepatic gluconeogenesis. BMB Rep. 46, 567-574. http://dx.doi.org/10.5483/BMBRep.2013.46.12.248.

Oriente, F., Iovino, S., Cabaro, S., Cassese, A., Longobardi, E., Miele, C., Ungaro, P., Formisano, P., Blasi, F., Beguinot, F., 2011. Prep1 controls insulin glucoregulatory function in liver by transcriptional targeting of SHP1 tyrosine phosphatase. Diabetes 60, 138-147. http://dx.doi.org/10.2337/db10-0860.

Park, S., Ahn, I.S., Kim da, S., 2010. Central infusion of leptin improves insulin resistance and suppresses beta-cell function, but not beta-cell mass, primarily through the sympathetic nervous system in a type 2 diabetic rat model. Life Sci. 86, 854-862. http://dx.doi.org/10.1016/j.lfs.2010.03.021.

Park, S., Hong, S.M., Sung, S.R., Jung, H.K., 2008. Long-term effects of central leptin and resistin on body weight, insulin resistance, and beta-cell function and mass by the modulation of hypothalamic leptin and insulin signaling. Endocrinology 149, 445-454. http://dx.doi.org/10.1210/en.2007-0754.

Penn, D.M., Jordan, L.C., Kelso, E.W., Davenport, J.E., Harris, R.B., 2006. Effects of central or peripheral leptin administration on norepinephrine turnover in defined fat depots. Am. J. Physiol. Regul. Integr. Comp. Physiol. 291, R1613-R1621. http://dx.doi.org/10.1152/ajpregu.00368.2006.

Pocai, A., Morgan, K., Buettner, C., Gutierrez-Juarez, R., Obici, S., Rossetti, L., 2005. Central leptin acutely reverses diet-induced hepatic insulin resistance. Diabetes 54, 3182-3189. http://dx.doi.org/10.2337/diabetes.54.11.3182.

Ramsay, T.G., Richards, M.P., 2004. Hormonal regulation of leptin and leptin receptor expression in porcine subcutaneous adipose tissue. J. Anim. Sci. 82, 3486-3492.

Roman, E.A., Reis, D., Romanatto, T., Maimoni, D., Ferreira, E.A., Santos, G.A., Torsoni, A.S., Velloso, L.A., Torsoni, M.A., 2010. Central leptin action improves skeletal muscle AKT, AMPK, and PGC1 alpha activation by hypothalamic PI3Kdependent mechanism. Mol. Cell Endocrinol. 314, 62-69. http://dx.doi.org/ 10.1016/j.mce.2009.08.007.

Rodríguez, A., Catalán, V., Gómez-Ambrosi, J., Frühbeck, G., 2011. Aquaglyceroporins serve as metabolic gateways in adiposity and insulin resistance control. Cell Cycle 10, 1548-1556. http://dx.doi.org/10.4161/cc.10.10.15672.

Sahu, A., 2008. Effects of chronic central leptin infusion on proopiomelanocortin and neurotensin gene expression in the rat hypothalamus. Neurosci. Lett. 440, 125-129. http://dx.doi.org/10.1016/j.neulet.2008.05.083.

Sakai, T., Kusakabe, T., Ebihara, K., Aotani, D., Yamamoto-Kataoka, S., Zhao, M., Gumbilai, V.M., Ebihara, C., Aizawa-Abe, M., Yamamoto, Y., Noguchi, M., Fujikura, J., Hosoda, K., Inagaki, N., Nakao, K., 2014. Leptin restores the insulinotropic effect of exenatide in a mouse model of type 2 diabetes with increased adiposity induced by streptozotocin and high-fat diet. Am. J. Physiol. Endocrinol. Metab. 307, E712-E719. http://dx.doi.org/10.1152/ajpendo.00272.2014.

Saladin, R., De Vos, P., Guerre-Millo, M., Leturque, A., Girard, J., Staels, B., Auwerx, J., 1995. Transient increase in obese gene expression after food intake or insulin administration. Nature 377, 527-529. http://dx.doi.org/10.1038/377527a0.

Scarpace, P.J., Matheny, M., Moore, R.L., Tumer, N., 2000. Impaired leptin responsiveness in aged rats. Diabetes 49, 431-435. http://dx.doi.org/10.2337/ diabetes.49.3.431.

Sharma, A., Bartell, S.M., Baile, C.A., Chen, B., Podolsky, R.H., McIndoe, R.A., She, J.X. 2010. Hepatic gene expression profiling reveals key pathways involved in leptin-mediated weight loss in ob/ob mice. PLoS One 5, e12147. http:// dx.doi.org/10.1371/journal.pone.0012147.

Sole, S.S., Srinivasan, B.P., 2012. Aqueous extract of tamarind seeds selectively increases glucose transporter-2, glucose transporter-4, and islets' intracellular calcium levels and stimulates $\beta$-cell proliferation resulting in improved glucose homeostasis in rats with streptozotocin-induced diabetes mellitus. Nutr. Res. 32, 626-636. http://dx.doi.org/10.1016/j.nutres.2012.06.015.
Suresha, R.N., Ashwini, V., Pragathi, B., Kalabharathi, H.L., Satish, A.M., Pushpa, V.H. Jayanthi, M.K., Snehalatha, P., 2013. The effect of carvedilol on blood glucose levels in normal albino rats. J. Clin. Diagn. Res. 7, 1900-1903. http://dx.doi.org 10.7860/JCDR/2013/6435.3346.

Suzuki, Y., Kurose, Y., Takahashi, H., Asakuma, S., Azuma, Y., Kobayashi, S., 2010. The differences in feeding-inhibitory responses to peripheral and central leptin between non-lactating and lactating rats. J. Endocrinol. 207, 105-111. http:// dx.doi.org/10.1677/JOE-09-0463.

Tanaka, T., Nagatani, S., Bucholtz, D.C., Ohkura, S., Tsukamura, H., Maeda, K. Foster, D.L., 2000. Central action of insulin regulates pulsatile luteinizing hormone secretion in the diabetic sheep model. Biol. Reprod. 62, 1256-1261. http://dx.doi.org/10.1095/biolreprod62.5.1256.

Tanida, M., Yamamoto, N., Morgan, D.A., Kurata, Y., Shibamoto, T., Rahmouni, K. 2015. Leptin receptor signaling in the hypothalamus regulates hepatic autonomic nerve activity via phosphatidylinositol 3-kinase and AMP-activated protein kinase. J. Neurosci. 35, 474-484. http://dx.doi.org/10.1523/JNEUROSCI.1828-14.2015.

Taniguchi, C.M., Ueki, K., Kahn, R., 2005. Complementary roles of IRS-1 and IRS-2 in the hepatic regulation of metabolism. J. Clin. Invest. 115, 718-727. http:/ dx.doi.org/10.1172/JCI23187.

van Dijk, G., Donahey, J.C., Thiele, T.E., Scheurink, A.J., Steffens, A.B., Wilkinson, C.W. Tenenbaum, R., Campfield, L.A., Burn, P., Seeley, R.J., Woods, S.C., 1997. Central leptin stimulates corticosterone secretion at the onset of the dark phase. Diabetes 46, 1911-1914. http://dx.doi.org/10.2337/diab.46.11.1911.

Wabitsch, M., Jensen, P.B., Blum, W.F., Christoffersen, C.T., Englaro, P., Heinze, E. Rascher, W., Teller, W., Tornqvist, H., Hauner, H., 1996. Insulin and cortisol promote leptin production in cultured human fat cells. Diabetes 45, 1435-1438. http://dx.doi.org/10.2337/diab.45.10.1435.

Wang, M.Y., Chen, L., Clark, G.O., Lee, Y., Stevens, R.D., Ilkayeva, O.R., Wenner, B.R. Bain, J.R., Charron, M.J., Newgard, C.B., Unger, R.H., 2010. Leptin therapy in insulin-deficient type I diabetes. Proc. Natl. Acad. Sci. U. S. A. 107, 4813-4819. http://dx.doi.org/10.1073/pnas.0909422107.

Wang, Y., Vera, L., Fischer, W.H., Montminy, M., 2009. The CREB coactivator CRTC2 links hepatic ER stress and fasting gluconeogenesis. Nature 460, 534-537. http://dx.doi.org/10.1038/nature08111.

Wu, D., Yang, M., Chen, Y., Jia, Y., Ma, Z.A., Boden, G., Li, L., Yang, G., 2014. Hypothalamic nesfatin-1/NUCB2 knockdown augments hepatic gluconeogenesis that is correlated with inhibition of mTOR-STAT3 signaling pathway in rats. Diabetes 63, 1234-1247. http://dx.doi.org/10.2337/db13-0899.

Xiao, H., Yin, T., Wang, X.Y., Uchida, T., Chung, J., White, M.F., Yang, Y.C., 2002. Specificity of interleukin-2 receptor gamma chain superfamily cytokines is mediated by insulin receptor substrate-dependent pathway. J. Biol. Chem. 277, 8091-8098. http://dx.doi.org/10.1074/jbc.M106650200.

Xiong, Y., Zhang, J., Liu, M., An, M., Lei, L., Guo, W., 2014. Human leptin protein activates the growth of HepG2 cells by inhibiting PERK-mediated ER stress and apoptosis. Mol. Med. Rep. 10, 1649-1655. http://dx.doi.org/10.3892/ mmr.2014.2373.

Xu, A.W., Kaelin, C.B., Takeda, K., Akira, S., Schwartz M.W., Barsh, G.S., 2005. PI3K integrates the action of insulin and leptin on hypothalamic neurons. J. Clin. Invest. 115, 951-958. http://dx.doi.org/10.1172/JCI24301.

Yavropoulou, M.P., Kotsa, K., Anastasiou, O., O'Dorisio, T.M., Pappas, T.N., Yovos, J.G. 2009. Effect of intracerebroventricular infusion of insulin on glucose-dependent insulinotropic peptide in dogs. Neurosci. Lett. 460, 148-151. http://dx.doi.org/ 10.1016/j.neulet.2009.05.052.

Zolotnik, I.A., Figueroa, T.Y., Yaspelkis 3rd, B.B., 2012. Insulin receptor and IRS-1 coimmunoprecipitation with SOCS-3, and IKK $\alpha / \beta$ phosphorylation are increased in obese Zucker rat skeletal muscle. Life Sci. 91, 816-822. http://dx.doi.org 10.1016/j.lfs.2012.08.038. 